\title{
Comparison Study for TSPA-VA Methodology
}

Cliff Ho (SNL), Bruce Robinson (LANL), Bo Bodvarsson (LBNL)

Note: The analyses contained herein have been conducted under the following SNL Quality Assurance Procedures:

- QAIP 2-4 Rev. 4: Conducting and Documenting Analyses/Calculations

- QAIP 6-2 Rev. 5: Preparing, Reviewing and Issuing Technical Information Documents

- QAIP 17-1 Rev 4: Creating, Protecting and Processing Submitting CRWM Reconds

- QAIP 17-2 Rev 4: Processing of Technical Data on the Yucca Mountain Site Characterization Project

The data generated in this study are not qualified unless otherwise noted. The codes used in the analyses (TOUGH2 (SNL v3.1.1 and v3.1.2) and FEHM) were not configured to the latest revision (Rev. 4) of SNL QAIP 19-1 (Software Quality Assurance Requirements) at the time the analyses were conducted. Qualification of the codes is currently underway. This web document (YO708-98) has been approved by TRW/SIG for public release.

\section{Purpose of this Web Site}

The objective of this web site is to provide a real-time communication tool for multi-organizational participants of the Yucca Mountain Project during the development of unsaturated-zone (UZ) flow and transport models for Total Systems Performance Assessment (TSPA) calculations for the Viability Assessment (TSPA-VA). This web site chronologically documents numerical simulations and sensitivity analyses that support some of the bases, approaches, and decisions regarding the methodology that will be used for flow and transport calculations in TSPA-VA.

\section{Abstract}

A comparison study is being performed to determine the feasibility of performing two different options for TSPA-VA calculations of radionuclide transport. The first option consists of performing the flow calculations with TOUGH2 (Pruess, 1991, 1987) and processing the output files for transport calculations using the FEHM particle tracker (Zyvoloski et al., 1995; Robinson et al., 1997). The second option consists of using properties generated by a calibrated TOUGH 2 model in FEHM simulations of both flow and transport.

The two options arose from the nature of the responsibilities that have been assigned to Lawrence Berkeley National Laboratory (LBNL) and Los Alamos National Laboratory (LANL) within the Yucca Mountain Project (YMP). LBNL is currently responsible for the development and calibration of the UZ site-scale model of Yucca Mountain, while LANL has been responsible for the development of flow and transport models of Yucca Mountain. The two options described above reflect the use of different combinations of individual responsibilities to develop flow and transport models for TSPA-VA.

The suite of simulations presented in this web site show that both options are viable methods to provide flow and transport calculations for TSPA-VA. However, to maintain consistency with the 3-D UZ site-scale model and data set that have been calibrated using TOUGH2, a decision was made to use TOUGH2 to simulate UZ flow fields while using FEHM as a particle tracker to simulate radionuclide transport within those flow fields.

Additional findings regarding the numerical weighting schemes used in TOUGH2 and FEHM were also revealed. A modified upstream weighting scheme will be used to simulate the UZ flow fields to most accurately account for flow between vitric and zeolitic matrix units.

The remainder of this web site describes a systematic comparison of options 1 and 2 starting with 1-D simulations and finishing with 2-D simulations. Discussions, data, and plots of the findings are also presented.

\section{1-D Flow and Transport Simulations}

As a first step, the participants agreed to look at a 1-D model of borehole SD-9. Properties (4/29/97) that were estimated from inverse simulations using ITOUGH2 were obtained from LBNL (Bodvarsson et al., 1997) (see Table 1). The fracture-matrix conceptual model consists of using upstream saturation as a multiplier for fracture-matrix flux in the non-welded units and upstream relative permeability as a multiplier for fracture-matrix flux in the welded units (refer to Ho (1997) for more information on fracture-matrix interaction models). The base-case infiltration is assumed to be $3.6 \mathrm{~mm} / \mathrm{year}$ at SD-9. 


\section{Option 1 1-D Flow Results}

The results include fracture and matrix saturations (Figure 1), normalized fluxes (Figure 2), and fracture-matrix flux interactions (Figure 3). For each set of results, two simulations are presented: one in which the top of the Calico Hills is zeolitic, and one in which the top of the Calico Hills is vitric. Although SD-9 contains a vitric layer just beneath the basal vitrophyre, the original SD-9 column from LBNL did not contain a vitric unit there--only a zeolitized one. This was attributed to the fact that the column was extracted from a 3-D model, and the coarseness of the 3-D model prevented inclusion of the vitric unit there. Nevertheless, the 1-D column was fine enough such that the top of the Calico Hills, represented by an element using chlz properties, could simply be replaced with an element using chlv (vitric) properties without violating the structure of SD-9.

The results show that the inclusion of a vitric layer causes the matrix saturation at that element to be lowered significantly because of its increased permeability. This lower saturation matches the observed data better. Also, the inclusion of a vitric Calico Hills unit causes the flow to be transferred almost entirely to the matrix in that region. Without the vitric layer, the flow stays primarily in the fractures. These results indicate the importance of including the proper strata in the Calico Hills for transport calculations. It also supports the validity of the LBNL estimated properties and the use of those properties in models that are more refined than the mesh in which the properties were generated.

A TOUGH2 simulation has also been performed using a refined 1-D mesh at SD-9 (5/27/97). The refined 1-D mesh contains 91 matrix elements and 91 fracture elements and was generated using a pre-processor written by Susan Altman of SNL. The same base-case properties and fracture-matrix models were used as in the previous cases. The results are similar to the results of the LBNL mesh using a vitric element at the top of the Calico Hills. The simulated fracture and matrix saturations are shown in Eigure 4 along with observed matrix saturations at SD-9. The flux values are somewhat different as shown in Eigure 5, with less water partitioned into the matrix units of the Calico Hills. Also, it should be noted that the inclusion of a vitric unit in the LBNL coarse mesh was done by simply "swapping" the ch1z element with a ch1v element. Therefore, the vitric layer in the coarse model is larger than in the refined mesh. Finally, the simulated fracture-matrix fluxes of the refined mesh (Figure 6) cannot be directly compared with the results of the coarser mesh because the refined mesh used a smaller vertical cross-sectional area and, hence, resulted in smaller mass flows. The infiltration rates for the coarse and refined meshes are $7.76 \mathrm{e}-4 \mathrm{~kg} / \mathrm{s}$ and $2.85 \mathrm{e}-6 \mathrm{~kg} / \mathrm{s}$, respectively. These both correspond to 3.6 $\mathrm{mm} / \mathrm{year}$. While the results of the coarse and refined meshes cannot be compared directly, they both indicate that the inclusion of a vitric layer allows greater partitioning of flow from the fractures to the matrix.

The borehole matrix saturations of SD-9 shown in Figures 1 and 4 have been qualified under DTN: GS950408312231.004.

\section{Option 1 1-D Transport Results}

\section{$(5 / 30 / 97)$}

Radionuclide transport simulations have been carried out on the TOUGH2 simulations described above. The procedure for performing the transport calculations was as follows: 1) produce 1D, dual permeability flow field data and grid information from the TOUGH2 flow simulations; 2) post-process these results to generate FEHM input files that contain the flow field and grid information; 3) perform particle tracking simulations with FEHM using the flow field from the TOUGH2 simulation, without invoking FEHM's flow simulator. From a "code capabilities" standpoint, the results illustrate that this process has been implemented and that this method of performing radionuclide transport calculations is feasible. Some of the processing software used for this test study was written specifically for one-dimensional grids, and thus for more complex model geometries, more general conversion software must be developed. This will be a straightforward task compared to the revisions to FEHM required to accept the flow fields. Thus the majority of the up-front work needed to provide this option is complete and tested.

Details of the transport simulations are: particle tracking, 500,000 particles for each radionuclide; instantaneous (pulse) release of 1 mole of radionuclide at $t=0$; advection and matrix diffusion $(D=1 . e-11 \mathrm{~m} 2 / \mathrm{s})$, no hydrodynamic dispersion; for Tc-99, no sorption; for $\mathrm{Np}-237, \mathrm{Kd}=2.5 \mathrm{cc} / \mathrm{g}$ in zeolitic units, 0 elsewhere.

Figure 7 shows the breakthrough curves at the water table for Tc-99 and Np-237 for the case in which the first vitric Calico Hills unit (chn1v) is not present. Because the flow is fracture-dominated from the repository to the water table, very short travel times are predicted. Np-237 exhibits longer travel times and a lower peak due to diffusion into the matrix and sorption on the zeolitic tuffs. Figure 8 illustrates that when the chn $1 \mathrm{v}$ unit is included, the transition to matrix-dominated flow results in much longer travel times for non-sorbing and sorbing radionuclides. The bi-modal breakthrough curve is a result of the relative partitioning of flow and transport in the fractures and matrix of the zeolitic tuffs. The two hydrologic cases are compared directly in Eigure 9 for Tc- 99 and Eigure 10 for Np-237. The influence of the relatively thin chn1v unit is dramatic ( 2 to 3 orders of magnitude longer peak travel times). These conclusions are tentative since the "Refined grid" simulations shown in Figures 9 and 10, which included the chn1v unit, show that it is possible that the level of grid refinement employed in the results of Figures 7 and 8 was insufficient to capture the transport simulations accurately. The conclusion is uncertain at present because the refined grid case has a different thickness for the chn1v unit than the coarse grid result to which it is compared. Therefore, we do not know how much of the difference is due to insufficient grid resolution and how much is attributable to the different layer thicknesses. Future simulations should be carried out to address this issue. At this point, the results demonstrate the potential of relatively thin, non-welded hydrogeologic units to convert fracture flow into matrix flow, with corresponding large improvements in predicted performance of the UZ transport barrier. 
Option 2 1-D Flow and Transport Results

\section{(7/28/97)}

Option 2 consists of using the hydrologic parameter set determined from the analysis of borehole fluid saturation data as input to an FEHM simulation of flow and transport. This required that the weighting schemes for determining the fracture-matrix coupling be implemented into FEHM. Both the upstream relative permeability weighting and the upstream saturation weighting models have now been incorporated into FEHM and the flow and transport results presented below use these weighting schemes. In FEHM, the weighting factor for the saturation model is $S^{\wedge} \mathbf{N}$, where $\mathbf{N}$ is a power of 1 or greater. In this study, $\mathbf{N}=1$ is used in the saturation weighting model for the nonwelded units, and the relative permeability weighting is used in the welded units, as specified in the inversion to obtain the parameter sets.

Eigure 11 shows the computed matrix saturations using FEHM, along with the TOUGH2-computed saturation profile (the TOUGH2 simulation on the refined grid is shown in this and subsequent plots). The very close agreement in the computed saturation profiles using the two codes is evidence of the equivalent implementation of the flow models in the two codes. The breaks in saturation profiles and the corresponding jumps in saturation levels are reproduced using FEHM to a high degree of similarity to the TOUGH2 solution. There are slight differences at the interfaces of some hydrologic units that should be explored further so that they may be more fully understood. However, based on this comparison of matrix saturations (the primary data set used in the inversions), FEHM simulations will maintain the calibration achieved using the TOUGH2 code as long as the same hydrologic parameter sets are used. Therefore, option 2 is seen to be a viable method for TSPA-VA.

There are other model results such as fracture saturation and relative flow rate through the fractures and matrix that are useful to compare for consistency even though they are solely computed quantities for which no direct comparison to data is possible. Note that these differences are irrelevant to the question of whether the models are calibrated, since we have already demonstrated the equivalence of the models with regard to matrix saturations. Nonetheless, agreement of the codes to this level will provide more confidence in the numerical implementation of both codes, and thus is desirable. Figure 11 also shows the computed fracture saturations of the two codes. Over most of the model, the agreement is excellent, with two exceptions. First, at interfaces between units in which the flow is transitioning between fracture and matrix flow, the FEHM simulations predict higher fracture saturations. This could be caused by slight differences in the implementation of the fracture-matrix weighting schemes, or subtle differences in the weighting schemes within a continuum. These possibilities should be investigated.

Second, the fracture saturation throughout the Calico Hills and underlying units are different in the two models. The importance of this difference is seen more easily in Eigure 12, a plot of normalized flux in the fractures and matrix for the two codes. The fracture saturations, and more importantly the relative fracture fluxes are different throughout the Calico Hills unit. This difference will give rise to different performance of the UZ system with respect to radionuclide transport, and thus is important to understand. There was a difference in the thickness of the first vitric Calico Hills unit due to the method used to assign properties to this unit in the TOUGH2 simulation. To check whether this difference accounts for the discrepancy in the models, an additional FEHM simulation was performed with a $4 \mathrm{~m}$ thick vitric layer (as opposed to $10 \mathrm{~m}$ ). The relative fluxes in this region of the model are shown on an expanded scale in Eigure 13. The FEHM solution with the $4 \mathrm{~m}$ thick vitric unit has a different behavior (the open circles in the figure), but the difference does not change the flow split in the underlying unit. Another possibility that was tested is that the differences are due to grid resolution effects. Rerunning the FEHM calculation on a coarse grid (not shown in the figures) ruled out this explanation as well. Further work is required to determine the nature of this discrepancy, but transport simulations presented below are first required to determine how much such differences are likely to matter for radionuclide migration.

Transport results: A comparison of the water table breakthrough curves for the two sets of simulations is shown for Tc-99 in Eigure 14. The two transport simulations are for all intents and purposes equivalent. Both exhibit bimodal behavior caused by the flow split in the Calico Hills units between the fractures and matrix, and the breakthrough times and peak values for the two models agree closely. There is slightly more mass reaching the water table in the first peak for the FEHM model due the higher predicted fracture flow fraction in the Calico Hills. The arival of the second peak is somewhat retarded relative to the TOUGH2 simulation, a consequence of the slower flow rate through the matrix for the FEHM calculation. Nonetheless, the agreement is quite close. Similar results for Np are shown in Eigure 15. The greater flow fraction in the fractures for FEHM is accentuated for Np-237, resulting in an earlier first peak and higher peak value. Once again a check using a coarser grid showed that grid resolution was not the cause of the differences in the transport results. (Note: In a later section we show that the cause of the discrepancy is due to different numerical weighting schemes used in TOUGH2 and FEHM for the absolute and relative permeabilities.)

\section{1-D Harmonic k TOUGH2 Results}

\section{(7/31/97)}

The TOUGH2 simulations reported in the Option 2 comparison have been re-run using harmonic-weighting for absolute permeability and upstream weighting for relative permeability. This is similar to the weighting normally used in FEHM. Eigure 16 shows the fracture and matrix liquid saturations resulting from TOUGH2 and FEHM. The fracture liquid saturations are quite similar now, but the matrix saturations differ near the top of the TSw units. Fipure 17 shows the normalized mass flow rates in the fractures and matrix resulting from TOUGH2 and FEHM. The revised TOUGH2 run now shows GREATER fracture flow in the CHn, whereas the 
fracture flow in the previous TOUGH2 simulation (using upstream $\mathrm{k}$ ) was less in the CHn. This would presumably affect the transport results as well. It appears that the choice of either upstream $k$ or harmonic $k$ is rather important, and agreement must be made among participants.

\section{2-D Flow and Transport Simulations}

\section{(10/1/97)}

Previous comparisons have been restricted to 1-D columns along SD-9. We have recently completed a study using option 1 on a 2-D domain. A post-processor (T2FEHM2) was written to take general, multi-dimensional flow fields from a TOUGH2 dual-permeability simulation and create re-start files for use in FEHM particle tracking. This successful study verified the feasibility of using option 1 for multi-dimensional systems.

\section{Option 1 2-D Results Using Full Upstream and Harmonic Weighting}

A steady-state flow field was simulated using TOUGH2 on a 2-D east-west cross-section at a northing coordinate of $233,400 \mathrm{~m}$ (located in the middle of the repository). The 2-D mesh was created by Charles Haukwa at LBNL. The infiltration was distributed over the cross-section and was supplied by Alan Flint through LBNL. The mean infiltration over the cross-section was $8 \mathrm{~mm} / \mathrm{year}$ with a maximum of nearly $19 \mathrm{~mm} / \mathrm{year}$. The 2-D model had 2816 active matrix elements and 2816 active fracture elements. The domain was bounded on the west by Solitario Canyon Fault and on the east by Ghost Dance Fault. The single-phase (Richards' eq.) module EOS9 was used for the analysis. In addition, the base-case LBNL hydrologic properties (7/31/97) were used for the 2-D simulations (see Table 2) (DTN: LB971100001254.002; TDIF: 306482). Note that these properties are different from the properties used in the 1-D simulations. See Eigure 18 for a plot of the model domain and infiltration.

The steady-state TOUGH2 flow fields were post-processed and the resulting FEHM re-start files were given to Bruce Robinson for particle tracking. The mass flux at the water table vs. time is shown in Eigure 19, and the cumulative mass breakthrough at the water table vs. time is shown in Eigure 20. In each figure, results are shown for Tc-99 and Np-237. In addition, each figure contains results for two weighting schemes: 1) full upstream weighting, where both the relative and absolute permeabilities are upstream weighted, and 2) harmonic weighting of the intrinsic permeability in conjunction with upstream weighting of the relative permeability.

Significant discrepancies exist between the upstream and harmonic weighting results. The differences are postulated to be due to the behavior of the flow at the interface of the calico hills vitric and zeolitic units. In the upstream weighting simulation, water flows readily from the vitric matrix to the zeolitic matrix since the upstream values of the vitric units are used. However, the harmonic $k$ weighting simulations result in water partitioning out of the vitric matrix and into the vitric fractures because of the extremely low conductivity at the interface of the vitric and zeolitic matrix units. The combination of the harmonic absolute permeability, which is strongly weighted towards the lower permeability of the zeolotic matrix, and the upstream relative permeability, which uses the vitric matrix relative permeability, can be lower than the conductivity of either the vitric or zeolitic matrix units. As a result, Np-237 shows much earlier breakthrough in the harmonic weighting simulation because of increased flow through the fractures. A compromise between these two extreme weighting schemes is proposed in the next section that honors the saturated conductivity of the zeolitic matrix while maintaining the conductivity within the bounds of the zeolitic and vitric matrix units.

\section{Option 1 2-D Results Using Modified Upstream Weighting}

\section{$(10 / 16 / 97)$}

Yu-Shu Wu at LBNL proposed a modified upstream weighting scheme to address liquid flow at the interface of a vitric matrix overlying a zeolitic matrix. As discussed earlier, the full upstream weighting allowed a large flow of water into the zeolitic matrix, often exceeding its saturated conductivity. In addition, the harmonic weighting scheme potentially yielded conductivities at the vitric/zeolitic interface that were lower than either of the two units. The proposed modified upstream weighting scheme uses upstream weighting everywhere except at connections where a vitric matrix overlies a zeolitic matrix. At these connections, downstream weighting is used for the absolute and relative permeabilities to honor the relatively low conductivity of the zeolitic matrix. This method is implemented in TOUGH 2 by flagging these specific connection pairs and modifying the TOUGH 2 code to use downstream weighting for flagged connections. These changes were made to the 2-D model described in the previous section, and an SNL modified version of TOUGH2 (2v3.1.2) was used in the current analysis. No convergence problems were encountered.

Eigure 21 shows the results of the modified upstream weighting simulation. Two plots are presented that show the flux of Tc-99 and Np-237 at the water table as a function of time for three weighting schemes: 1) modified upstream, 2) full upstream, and 3) harmonic k. Results show that the modified upstream results are similar to the harmonic $\mathbf{k}$ results, but more flow occurs through the zeolitic matrix as indicated by the secondary peaks in the breakthrough curves. The modified upstream case also shows that more water partitions into the vitric fractures (from the vitric matrix) than in the full upstream case, honoring the low conductivity of the zeolitic matrix. These features are better illustrated in the cumulative Np-237 breakthrough curve for all three weighting schemes in Eigure 22. The proposed modified upstream weighting scheme is a compromise between the full upstream and harmonic weighting schemes and is thought to be more defensible from a physical standpoint. Therefore, the modified upstream weighting scheme will be used in 
UZ flow calculations for TSPA-VA.

Finally, breakthrough curves at the water table for Tc-99 and Np-237 are compared between TOUGH2 (harmonic k) and FEHM (harmonic k) results. Recall that all previous results in this section were derived from TOUGH2 flow simulations. Eigure 23 shows results from the TOUGH2 harmonic $k$ simulation (see Figure 19) along with results from a FEHM simulation of a 2-D model located near the cross-section of the TOUGH2 simulations (the FEHM simulation was part of a recent LANL milestone (Robinson et al., 1997)). The results show that the trends are quite similar for Tc-99 and Np-237, although the FEHM breakthrough curves are more diffuse relative to the TOUGH 2 curves. This may be attributed, in part, to the different location and/or refinement of the grids.

\section{References}

- Bodvarsson, G.S., T.M. Bandurraga, and Y.S. Wu, eds., 1997, The Site-Scale Unsaturated Zone Model of Yucca Mountain, Nevada, for the Viability Assessment, LBNL-40376, Lawrence Berkeley National Laboratory, Berkeley, CA (DTN: LB970601233129.001).

- Ho, C.K., 1997, Models of Fracture-Matrix Interactions During Multiphase Heat and Mass Flow in Unsaturated Fractured Porous Media, SAND97-1198C, in Proceedings of the Sixth Symposium on Multiphase Transport in Porous Media, 1997 ASME International Mechanical Engineering Congress and Exposition, Dallas, TX, Nov. 16-21.

- Pruess, K., 1987, TOUGH User's Guide, LBL-20700, SAND86-7104, NUREG/CR-4645, Lawrence Berkeley Laboratory, Berkeley, CA.

- Pruess, K., 1991, TOUGH2-A General-Purpose Numerical Simulator for Multiphase Fluid and Heat Flow, LBL-29400, Lawrence Berkeley Laboratory, Berkeley, CA.

- Robinson, B.A., A.V. Wolfsberg, H.S. Viswanathan, G.Y. Bussod, C.W. Gable, and A. Meijer, 1997, The Site-Scale Unsaturated Zone Transport Model of Yucca Mountain, Milestone SP25BM3, Los Alamos National Laboratory, Los Alamos, NM.

- Zyvoloski, G.A., B.A. Robinson, Z.V. Dash, and L.L. Trease, 1995, Users Manual for the FEHMN Application, LA-UR-94-3788, Rev. 1, Los Alamos National Laboratory, Los Alamos, NM.

\section{Back to Performance Assessment Page}

Please direct questions or comments to:

Cliff Ho

Sandia National Laboratories

P.O. Box 5800, MS-1324

Albuquerque, NM 87185-1324

(505) 848-0712

ckho@sandia.gov 
from Bodvarsson et al. (1997) (DTN: LB970601233129.001)

\begin{tabular}{|c|c|c|c|c|c|c|c|c|c|c|}
\hline Material & Porosity & Permeability & V.G. alpha & $\begin{array}{c}\text { V.G. } \\
\text { lambda }\end{array}$ & $\mathbf{S r}$ & $\begin{array}{c}\text { Wet } \\
(W / m-K)\end{array}$ & Dry $(W / m-K)$ & $\begin{array}{c}\text { Grain } \\
\text { Density }\end{array}$ & $\begin{array}{c}\text { Specific } \\
\text { Heat }\end{array}$ & Tortuosity \\
\hline tcwMI & $\longdiv { 6 . 6 0 \mathrm { E } - 0 2 }$ & $5.40 \mathrm{E}-18$ & $1.18 \mathrm{E}-06$ & $\overline{2.32 \mathrm{E}-01}$ & $1.30 \mathrm{E}-01$ & $1.66 \mathrm{E}+00$ & $7.20 \mathrm{E}-01$ & 2510 & 847 & 0.7 \\
\hline tcwM2 & $6.60 \mathrm{E}-02$ & $5.40 \mathrm{E}-18$ & $1.33 \mathrm{E}-06$ & $2.36 \mathrm{E}-01$ & $1.30 \mathrm{E}-01$ & $1.88 \mathrm{E}+00$ & $1.28 \mathrm{E}+00$ & 2510 & 837 & $\overline{\overline{0.7}}$ \\
\hline tcwM3 & $\longdiv { 1 . 4 0 \mathrm { E } - 0 1 }$ & $5.00 \mathrm{E}-17$ & $\overline{2.32 E-07}$ & 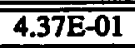 & $3.30 \mathrm{E}-01$ & $9.80 \mathrm{E}-01$ & $5.40 \mathrm{E}-01$ & 2470 & 857 & 0.7 \\
\hline ptnM1 & $3.69 \mathrm{E}-01$ & $1.60 \mathrm{E}-14$ & $\overline{4.05 E-05}$ & $\overline{\overline{2.33 \mathrm{E}-01}}$ & $1.00 \mathrm{E}-01$ & $5.00 \mathrm{E}-01$ & $3.50 \mathrm{E}-01$ & 2340 & 1080 & $\overline{0.7}$ \\
\hline ptnM2 & $2.34 \mathrm{E}-01$ & $3.76 \mathrm{E}-15$ & $1.09 \mathrm{E}-05$ & $\overline{5.18 \mathrm{E}-01}$ & $1.40 \mathrm{E}-01$ & 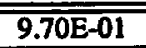 & $4.40 \mathrm{E}-01$ & 2400 & 849 & $\overline{0.7}$ \\
\hline ptnM3 & $3.53 \mathrm{E}-01$ & $1.43 \mathrm{E}-13$ & $4.49 \mathrm{E}-05$ & $\overline{\overline{2.74 E-01}}$ & $1.70 \mathrm{E}-01$ & $1.02 \mathrm{E}+00$ & $4.60 \mathrm{E}-01$ & 2370 & 1020 & 0.7 \\
\hline$\overline{\text { ptnM4 }}$ & $\longdiv { 4 . 6 9 \mathrm { E } - 0 1 }$ & $1.12 \mathrm{E}-13$ & $4.59 \mathrm{E}-05$ & $\overline{3.46 \mathrm{E}-01}$ & $1.00 \mathrm{E}-01$ & $8.20 \mathrm{E}-01$ & $3.50 \mathrm{E}-01$ & 2260 & 1330 & 0.7 \\
\hline ptnM5 & $4.64 \mathrm{E}-01$ & $\overline{2.10 \mathrm{E}-13}$ & $1.92 \mathrm{E}-04$ & 2.77E-01 & $1.00 \mathrm{E}-01$ & $6.70 \mathrm{E}-01$ & $\overline{2.30 \mathrm{E}-01}$ & 2370 & 1220 & $\overline{\overline{0.7}}$ \\
\hline tswMI & $\longdiv { 4 . 2 0 \mathrm { E } - 0 2 }$ & $6.72 \mathrm{E}-15$ & $1.06 \mathrm{E}-05$ & 2.67E-01 & $1.10 \mathrm{E}-01$ & $1.00 \mathrm{E}+00$ & $3.70 \mathrm{E}-01$ & 2510 & $\overline{834}$ & $\overline{\overline{0.7}}$ \\
\hline$\overline{\text { tswM2 }}$ & $1.46 \mathrm{E}-01$ & $1.33 \mathrm{E}-15$ & $\overline{\overline{4.07 E-05}}$ & 3.17E-01 & $4.00 \mathrm{E}-02$ & $1.62 \mathrm{E}+00$ & $1.06 \mathrm{E}+00$ & 2550 & 866 & 0.7 \\
\hline tswM3 & $1.35 \mathrm{E}-01$ & $\overline{4.99 \mathrm{E}-17}$ & $6.32 \mathrm{E}-06$ & 2.61E-01 & $6.00 \mathrm{E}-02$ & $1.58 \mathrm{E}+00$ & $4.10 \mathrm{E}-01$ & 2510 & 883 & 0.7 \\
\hline tswM4 & $8.90 \mathrm{E}-02$ & $1.46 \mathrm{E}-17$ & $7.81 \mathrm{E}-07$ & $3.44 \mathrm{E}-01$ & $1.80 \mathrm{E}-01$ & $2.33 \mathrm{E}+00$ & $1.56 \mathrm{E}+00$ & 2530 & 948 & 0.7 \\
\hline tswMS & $1.15 \mathrm{E}-01$ & $1.16 \mathrm{E}-16$ & $\overline{2.45 E-06}$ & $\overline{\overline{2.11 E-01}}$ & $8.00 \mathrm{E}-02$ & $1.80 \mathrm{E}+00$ & $\overline{6.50 \mathrm{E}-01}$ & 2540 & 900 & $\overline{\overline{0.7}}$ \\
\hline tswM6 & $7.10 \mathrm{E}-02$ & $1.30 \mathrm{E}-16$ & $\overline{\overline{5.62 E-07}}$ & 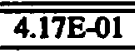 & $1.80 \mathrm{E}-01$ & $1.84 \mathrm{E}+00$ & $1.42 \mathrm{E}+00$ & 2560 & 865 & $\overline{\overline{0.7}}$ \\
\hline tswM7 & $2.00 \mathrm{E}-02$ & $6.49 \mathrm{E}-17$ & $1.02 \mathrm{E}-07$ & $3.69 \mathrm{E}-01$ & $5.00 \mathrm{E}-01$ & $2.08 \mathrm{E}+00$ & $1.69 \mathrm{E}+00$ & 2360 & 984 & 0.7 \\
\hline chiMv & $2.65 \mathrm{E}-01$ & $1.73 \mathrm{E}-12$ & $6.09 \mathrm{E}-05$ & $1.89 \mathrm{E}-01$ & $4.00 \mathrm{E}-02$ & $1.31 \mathrm{E}+00$ & $7.00 \mathrm{E}-01$ & 2310 & 1060 & 0.7 \\
\hline chlMz & $1.93 \mathrm{E}-01$ & $1.47 \mathrm{E}-17$ & 1.90E-07 & 3.62E-01 & $3.60 \mathrm{E}-01$ & $1.31 \mathrm{E}+00$ & $7.00 \mathrm{E}-01$ & 2310 & 1060 & 0.7 \\
\hline ch2Mv & $3.21 \mathrm{E}-01$ & $2.38 \mathrm{E}-13$ & $\overline{7.61 E-05}$ & $2.24 \mathrm{E}-01$ & $6.00 \mathrm{E}-02$ & $1.17 \mathrm{E}+00$ & $5.80 \mathrm{E}-01$ & 2240 & 1200 & 0.7 \\
\hline$\overline{c c h 3 \mathrm{Mz}}$ & $2.40 \mathrm{E}-01$ & $2.21 \mathrm{E}-17$ & $3.61 E-06$ & $2.26 \mathrm{E}-01$ & $2.00 \mathrm{E}-01$ & $1.20 \mathrm{E}+00$ & $\overline{6.10 \mathrm{E}-01}$ & 2350 & 1150 & 0.7 \\
\hline$\overline{c h 4 M z}$ & $1.69 \mathrm{E}-01$ & $1.32 \mathrm{E}-17$ & $1.50 \mathrm{E}-07$ & $\overline{4.76 \mathrm{E}-01}$ & $3.30 \mathrm{E}-01$ & $1.35 \mathrm{E}+00$ & 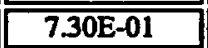 & $\overline{2440}$ & 1170 & $\overline{0.7}$ \\
\hline pp3Mv & $2.74 \mathrm{E}-01$ & $3.20 \mathrm{E}-15$ & $1.75 \mathrm{E}-05$ & 3.12E-01 & $7.00 \mathrm{E}-02$ & $1.26 \mathrm{E}+00$ & $\overline{6.60 \mathrm{E}-01}$ & 2580 & 841 & 0.7 \\
\hline $\mathrm{pp} 2 \mathrm{Mz}$ & $1.97 \mathrm{E}-01$ & 5.88E-17 & $\overline{1.69 \mathrm{E}-06}$ & $3.16 \mathrm{E}-01$ & $1.80 \mathrm{E}-01$ & $1.35 \mathrm{E}+00$ & $7.40 \mathrm{E}-01$ & 2510 & 644 & $\overline{0.7}$ \\
\hline tcwF1 & 2.33E-04 & $6.00 \mathrm{E}-12$ & $2.37 \mathrm{E}-03$ & $4.92 \mathrm{E}-01$ & $1.00 \mathrm{E}-02$ & $1.56 \mathrm{E}-04$ & $6.99 \mathrm{E}-06$ & 0.995 & 1010 & 0.7 \\
\hline tewF2 & $2.99 \mathrm{E}-04$ & $\overline{0.00 \mathrm{E}-12}$ & $2.37 \mathrm{E}-03$ & $\overline{\overline{4} 4.92 \mathrm{E}-01}$ & $1.00 \mathrm{E}-02$ & $2.00 \mathrm{E}-04$ & $\overline{8.97 \mathrm{E}-06}$ & 0.995 & $\overline{1010}$ & $\overline{0.7}$ \\
\hline tcwF3 & $7.05 \mathrm{E}-05$ & $2.40 \mathrm{E}-12$ & $9.12 \mathrm{E}-04$ & 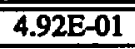 & $1.00 \mathrm{E}-02$ & $4.72 \mathrm{E}-05$ & $2.12 \mathrm{E}-06$ & 0.995 & 1010 & 0.7 \\
\hline ptnF1 & $4.84 \mathrm{E}-05$ & $3.09 \mathrm{E}-13$ & $1.10 \mathrm{E}-03$ & $4.96 \mathrm{E}-01$ & $1.00 \mathrm{E}-02$ & $\overline{3.24 \mathrm{E}-05}$ & $\overline{\overline{1.45 E-06}}$ & $\overline{0.995}$ & 1010 & $\overline{0.7}$ \\
\hline ptnF2 & 4.83E-05 & 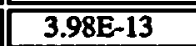 & $7.44 \mathrm{E}-05$ & $\overline{4.89 \mathrm{E}-01}$ & $1.00 \mathrm{E}-02$ & $3.24 \mathrm{E}-05$ & $1.45 \mathrm{E}-06$ & 0.995 & 1010 & $\overline{0.7}$ \\
\hline$\overline{p t n F 3}$ & $1.30 \mathrm{E}-04$ & $2.56 \mathrm{E}-12$ & $3.45 \mathrm{E}-03$ & $4.81 \mathrm{E}-01$ & $1.00 \mathrm{E}-02$ & $8.71 E-05$ & $3.90 \mathrm{E}-06$ & 0.995 & 1010 & 0.7 \\
\hline ptnF4 & 6.94E-05 & 1.17E-13 & $\overline{9.13 E-04}$ & $4.94 \mathrm{E}-01$ & $1.00 \mathrm{E}-02$ & 4.65E-05 & $2.08 \mathrm{E}-06$ & 0.995 & 1010 & 0.7 \\
\hline ptnF5 & $8.32 \mathrm{E}-05$ & 2.19E-13 & $1.11 \mathrm{E}-03$ & 4.92E-01 & $1.00 \mathrm{E}-02$ & $5.57 \mathrm{E}-05$ & $2.50 \mathrm{E}-06$ & 0.995 & 1010 & 0.7 \\
\hline tswF1 & $8.92 \mathrm{E}-05$ & $1.20 \mathrm{E}-12$ & $1.54 \mathrm{E}-04$ & $4.92 \mathrm{E}-01$ & $1.00 \mathrm{E}-02$ & $5.98 \mathrm{E}-05$ & $2.68 \mathrm{E}-06$ & 0.995 & 1010 & 0.7 \\
\hline tswF2 & $1.29 \mathrm{E}-04$ & $7.08 \mathrm{E}-13$ & 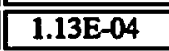 & $4.92 \mathrm{E}-01$ & $1.00 \mathrm{E}-02$ & $8.64 \mathrm{E}-05$ & $3.87 \mathrm{E}-06$ & $\overline{0.995}$ & $\overline{1010}$ & 0.7 \\
\hline tswF3 & $1.05 \mathrm{E}-04$ & $8.91 \mathrm{E}-13$ & 5.92E-05 & $4.92 \mathrm{E}-01$ & $1.00 \mathrm{E}-02$ & $7.04 \mathrm{E}-05$ & $3.15 E-06$ & 0.995 & 1010 & 0.7 \\
\hline tswF4 & $1.24 \mathrm{E}-04$ & $4.27 \mathrm{E}-13$ & 8.13E-05 & $4.92 \mathrm{E}-01$ & $1.00 \mathrm{E}-02$ & 8.31E-05 & $3.72 \mathrm{E}-06$ & 0.995 & 1010 & 0.7 \\
\hline tswF5 & $3.29 \mathrm{E}-04$ & $9.12 \mathrm{E}-13$ & $1.26 \mathrm{E}-04$ & $4.92 \mathrm{E}-01$ & $1.00 \mathrm{E}-02$ & $2.20 \mathrm{E}-04$ & $9.87 \mathrm{E}-06$ & 0.995 & 1010 & 0.7 \\
\hline$\overline{\text { tswF6 }}$ & $3.99 \mathrm{E}-04$ & $1.20 \mathrm{E}-12$ & 1.32E-04 & $4.92 \mathrm{E}-01$ & $1.00 \mathrm{E}-02$ & $2.67 \mathrm{E}-04$ & $1.20 \mathrm{E}-05$ & 0.995 & 1010 & 0.7 \\
\hline IswF7 & $4.92 \mathrm{E}-04$ & $1.20 \mathrm{E}-12$ & $1.19 \mathrm{E}-04$ & $4.92 \mathrm{E}-01$ & $1.00 \mathrm{E}-02$ & $3.30 \mathrm{E}-04$ & $1.48 \mathrm{E}-05$ & 0.995 & 1010 & 0.7 \\
\hline ch1Fy & $7.14 \mathrm{E}-05$ & $1.74 \mathrm{E}-13$ & $1.18 \mathrm{E}-03$ & $4.92 \mathrm{E}-01$ & $1.00 \mathrm{E}-02$ & $4.78 \mathrm{E}-05$ & $2.14 \mathrm{E}-06$ & 0.995 & 1010 & 0.7 \\
\hline chlFz & $1.10 \mathrm{E}-05$ & $3.67 \mathrm{E}-14$ & $\overline{1.34 \mathrm{E}-04}$ & 4.83E-01 & $1.00 \mathrm{E}-02$ & $\overline{7.37 \mathrm{E}-06}$ & 3.30E-07 & 0.995 & 1010 & $\overline{0.7}$ \\
\hline ch2Fv & $\sqrt{7.14 \mathrm{E}-05}$ & $2.88 \mathrm{E}-13$ & $1.18 \mathrm{E}-03$ & 4.92E-01 & $1.00 \mathrm{E}-02$ & $\overline{4.78 E-05}$ & $2.14 \mathrm{E}-06$ & 0.995 & 1010 & $\overline{\overline{0.7}}$ \\
\hline ch3Fz & $1.10 \mathrm{E}-05$ & $\overline{\overline{2.51 E-14}}$ & $1.14 \mathrm{E}-03$ & $\overline{4.92 \mathrm{E}-01}$ & $1.00 \mathrm{E}-02$ & $7.37 \mathrm{E}-06$ & $3.30 \mathrm{E}-07$ & 0.995 & 1010 & 0.7 \\
\hline$\overline{\overline{c h 4 F z}}$ & $1.10 \mathrm{E}-05$ & $2.51 \mathrm{E}-14$ & $1.14 \mathrm{E}-03$ & $4.92 E-01$ & $1.00 \mathrm{E}-02$ & $7.37 \mathrm{E}-06$ & 3.30E-07 & 0.995 & 1010 & 0.7 \\
\hline pp3Fv & 7.14E-05 & $7.08 \mathrm{E}-13$ & $1.42 \mathrm{E}-03$ & $4.92 \mathrm{E}-01$ & $1.00 \mathrm{E}-02$ & $\overline{4.78 E-05}$ & $2.14 \mathrm{E}-06$ & 0.995 & 1010 & $\overline{0.7}$ \\
\hline pp2Fz & $1.10 \mathrm{E}-05$ & $2.51 \mathrm{E}-14$ & $1.07 \mathrm{E}-03$ & $4.92 \mathrm{E}-01$ & $1.00 \mathrm{E}-02$ & 7.37E-06 & $3.30 \mathrm{E}-07$ & 0.995 & 1010 & $\overline{0.7}$ \\
\hline
\end{tabular}


Simulated Steady-State Matrix and Fracture Liquid Saturations

For SD-9 Using TOUGH2 and Base-Case Properties

Infiltration $=3.6 \mathrm{~mm} / \mathrm{year}$

Fncture-Mutrix Model:

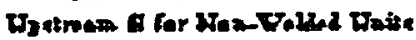

Upstrem $k$, for Velded Units

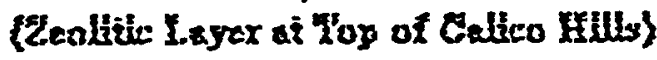

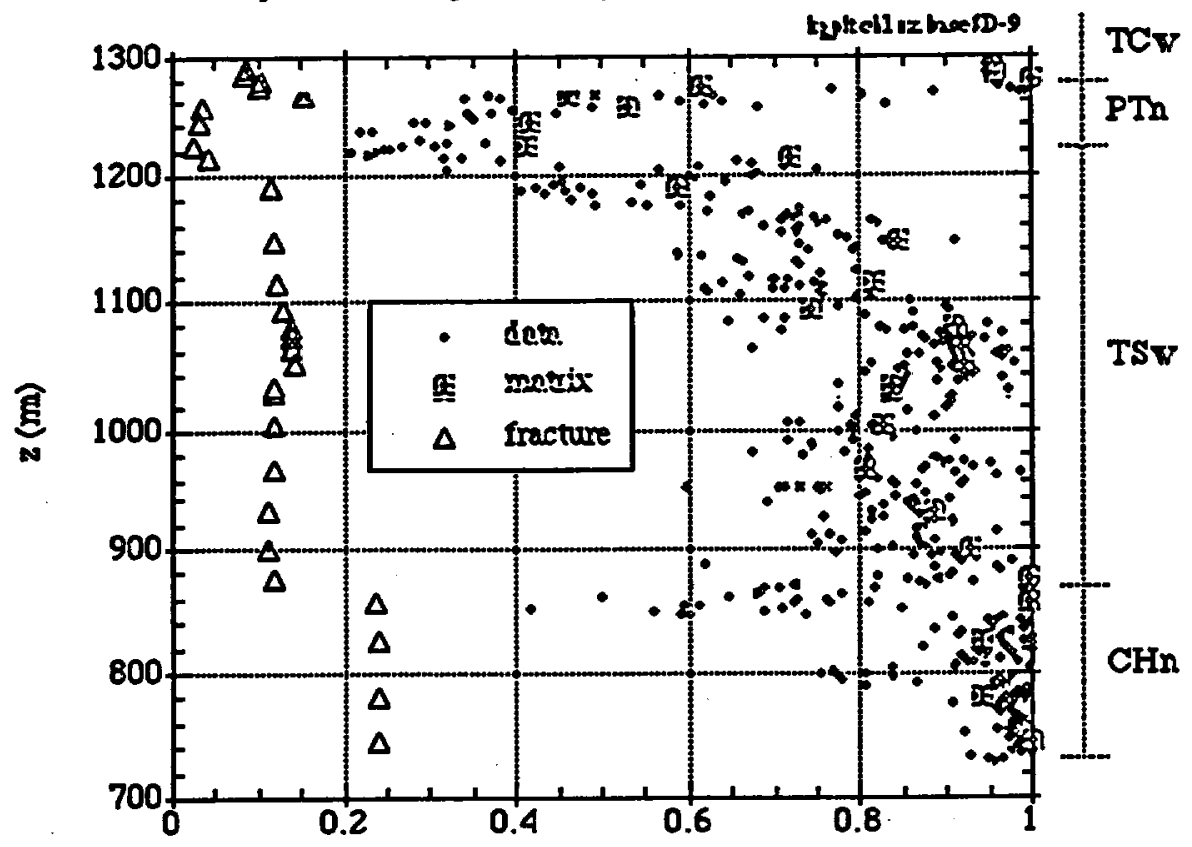

Liquid Saturation

(Yitrie Layer at Tov of Calien Hills)

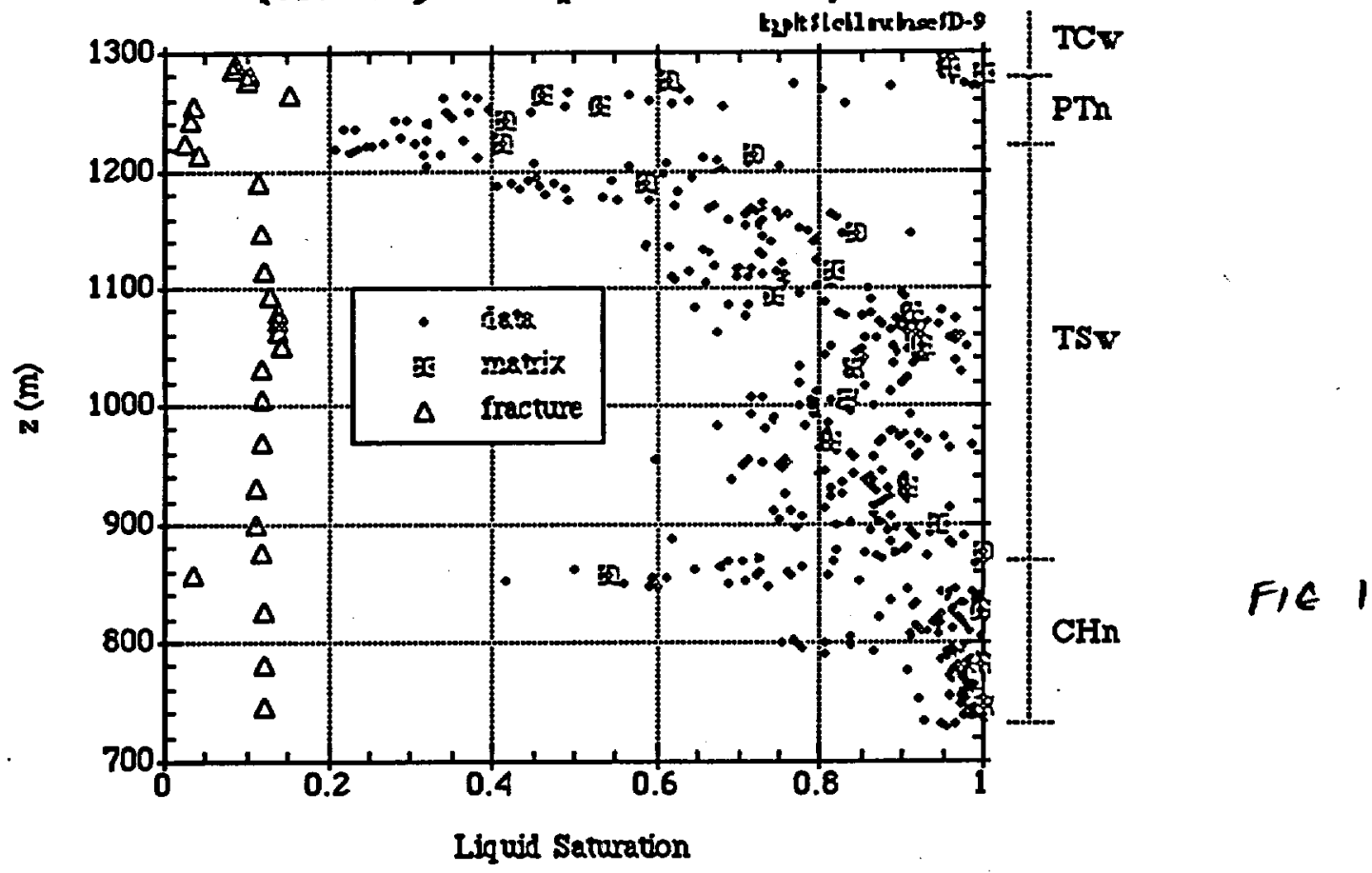


Simulated Steady-State Nomalized Hatrix and Fracture Fluxes

For SD-9 Using TOUGH2 and Base-Case Properties

Infiltration $=3.6 \mathrm{~mm} / \mathrm{year}$

Fnetur-Mutrix Model:

Upstream 8 for Non-Weled Units

Upstrem $k_{1}$ for Welded Units

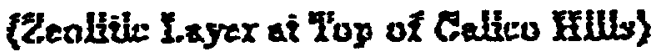

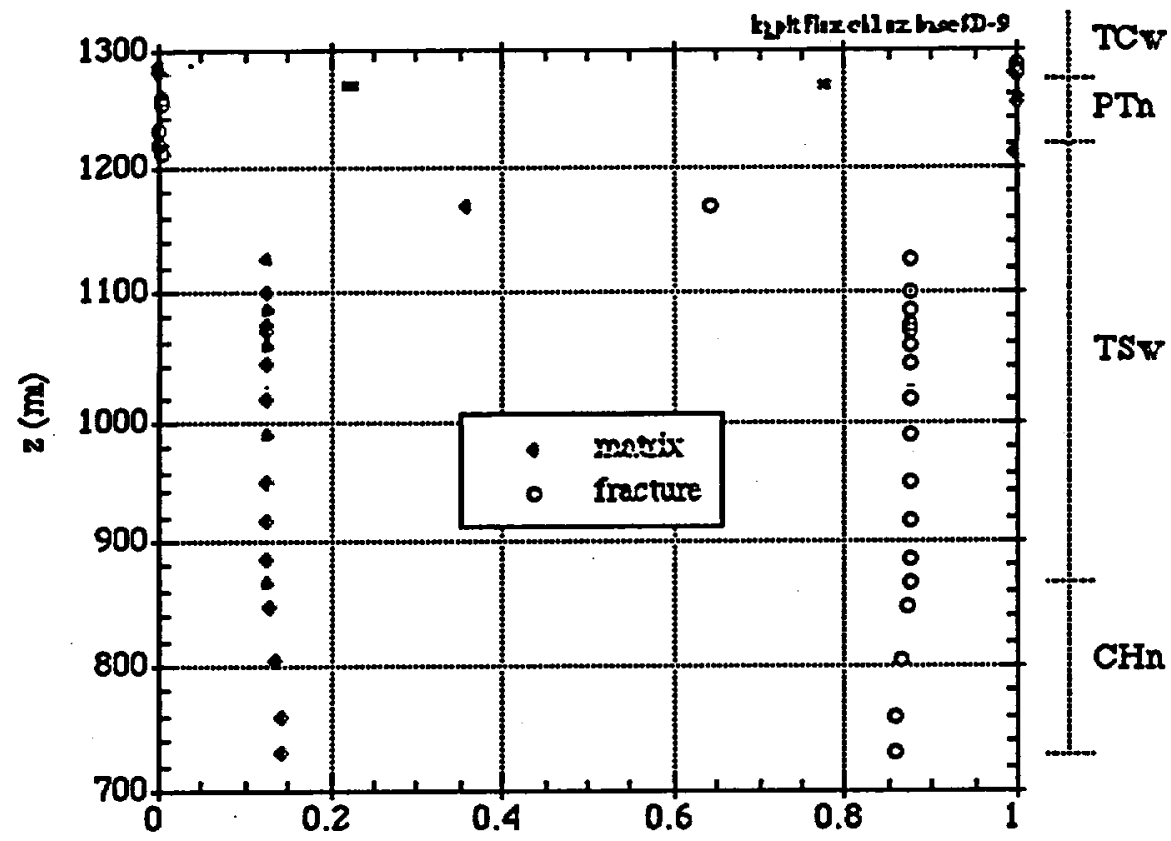

Liquid Mass Flow Divided by Infiltration Rate $\left(7.76 \times 10^{-4} \mathrm{~kg} / \mathrm{s}\right)$

(Vitric Layer al Top of Caliec kllus)

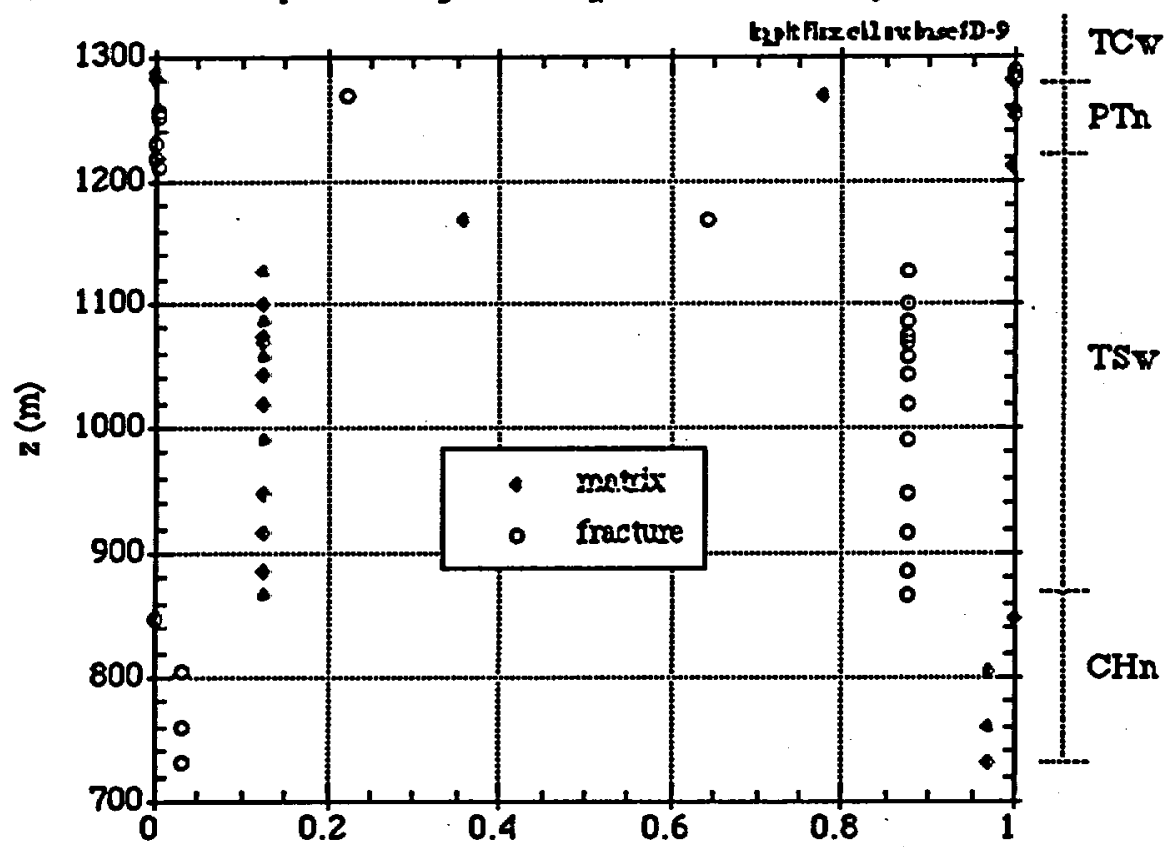

Fia 2

Liquid Mass Flow Divided by Infiltration Rate $\left(7.76 \times 10^{-4} \mathrm{~kg} / \mathrm{s}\right)$ 
Simulated Steady-State Fracture-Hatrix Flures

For SD-9 Using TOUGH2 and Base-Case Properties Infiltration $=3.6 \mathrm{~mm} / \mathrm{year}$

Fneture-Mutrix Model:

Upstram B for Non-Welded Units

Upstream $k$, for Velled Units

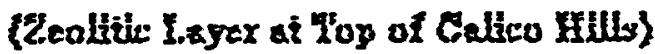

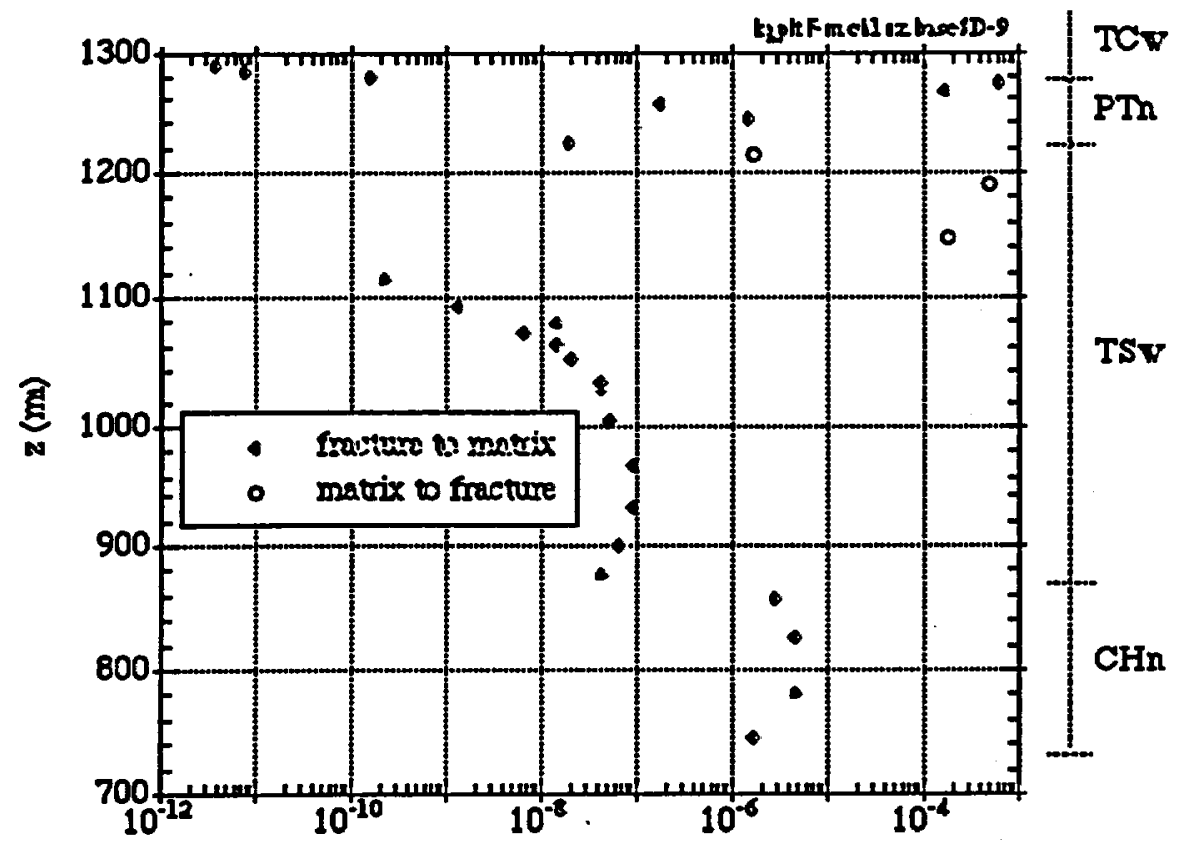

Mass Fibv Between Fractures and Matrix (kg/s)

(Flerie Layar as Top of Calleo filila)

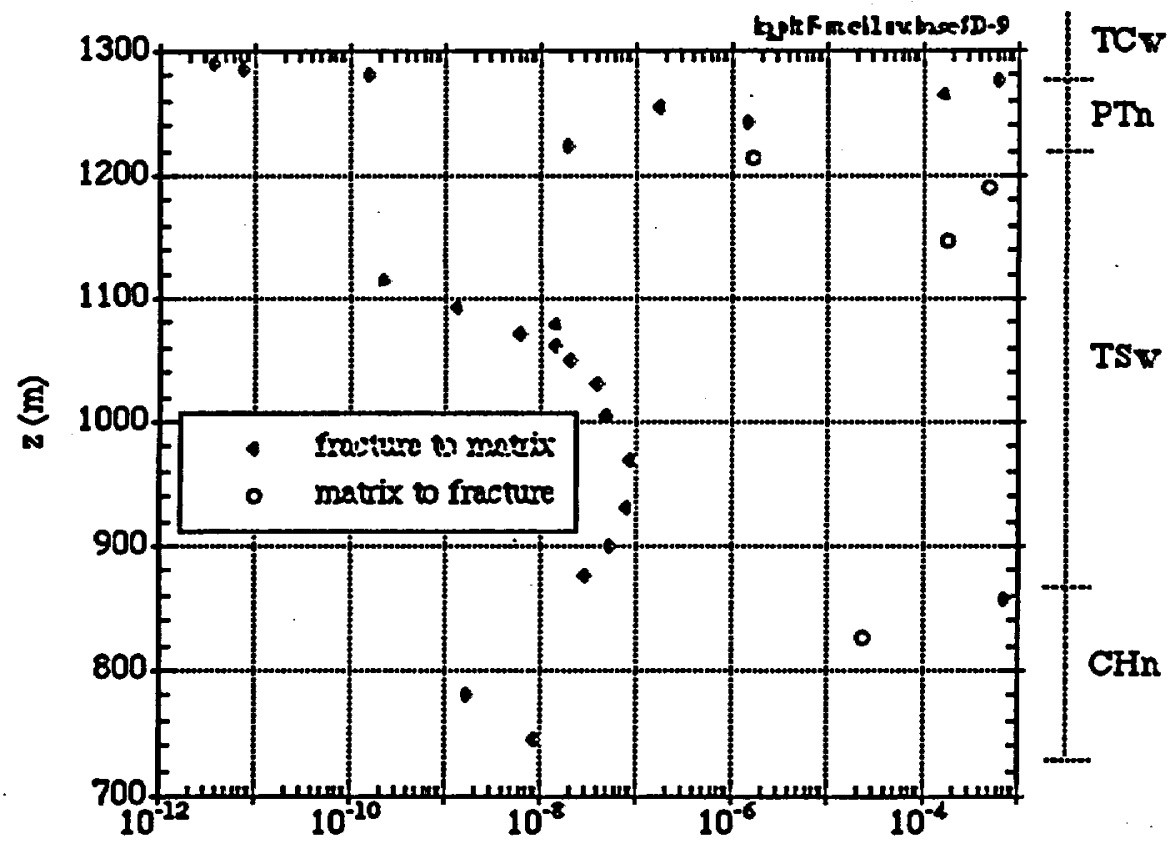

FIC 3

Mass Flow Between Fractures and Matrix (kg/s) 
Simulated Steady-State Hatrix and Fracture Liquid Saturations For SD-9 Using TOUGH2 and Base-Case Properties Infiltration $=3.6 \mathrm{~mm} /$ year Fneture-Marix Model:

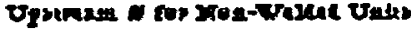
U

(IRefined Ifesh: 182 Tutal ESemanta)

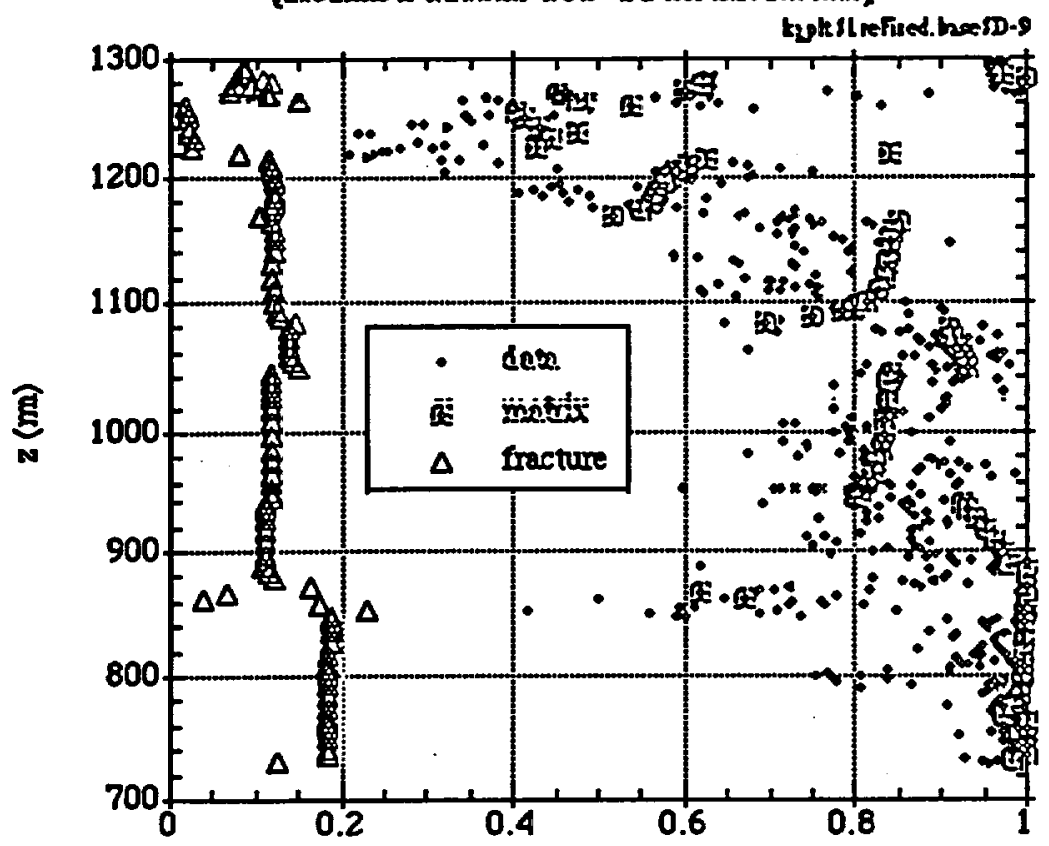

Liquid Saturation 
Simulated Steady-State Nomalized Hatrix and Fracture Fluxes

For SD-9 Using TOUGH2 and Base-Case Properties Infiltration $=3.6 \mathrm{~mm} /$ year

Fneture-Matrix Model:

Upstrean 8 for Non-Welded Units

Upstrean $k_{1}$ for Welded Units

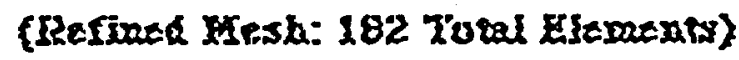

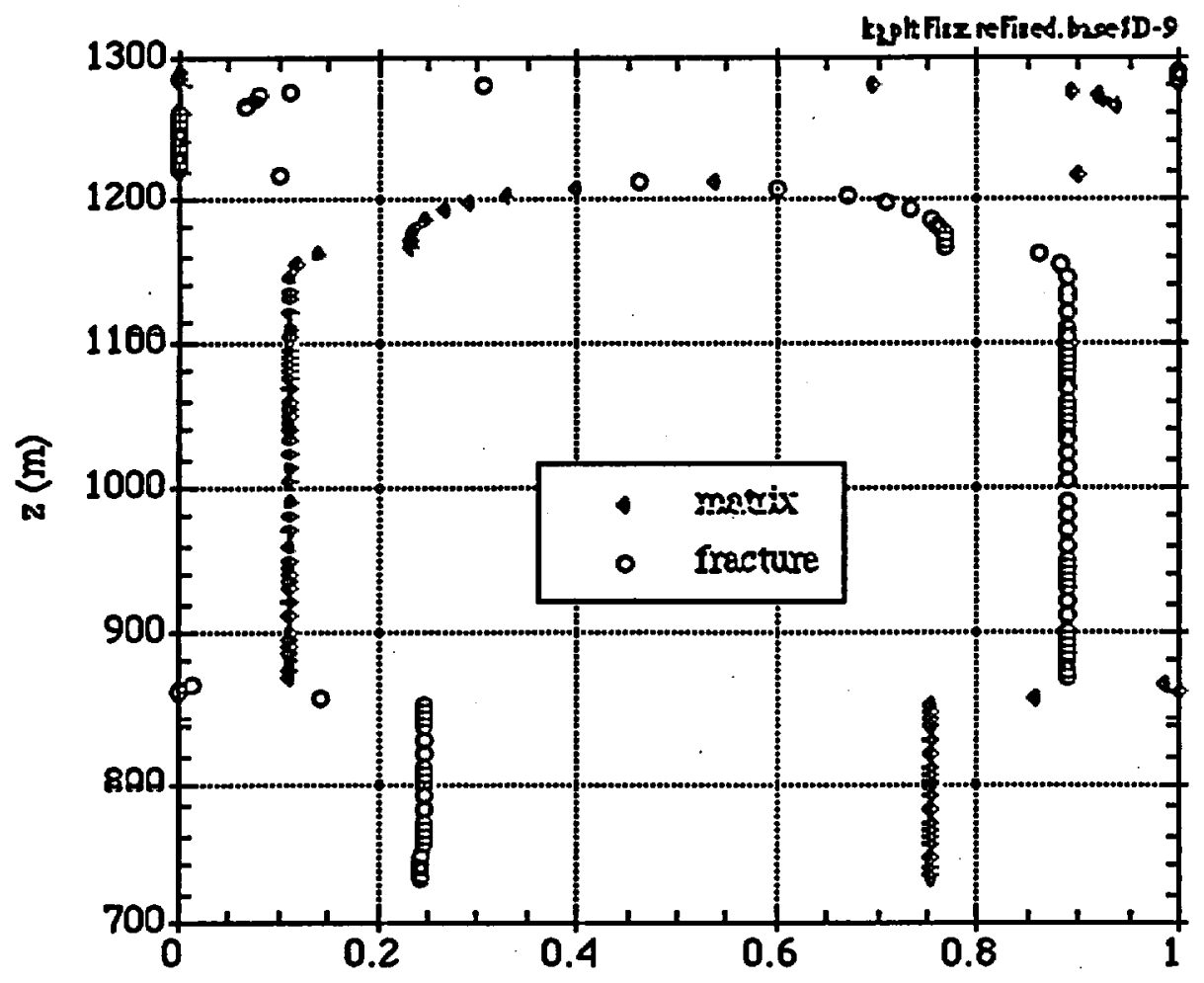

Liquid Mass Flow Divided by Infiltration Rate $\left(2.85 \times 10^{-6} \mathrm{~kg} / \mathrm{s}\right)$

FIG 5 
For SD-9 Using TOUGH2 and Base-Case Properties Infiltration $=3.6 \mathrm{~mm} /$ year Fneture-Matrix Model:

Upstrean \& for Non-Welled Units Upstrean $k_{1}$ for Welled Units

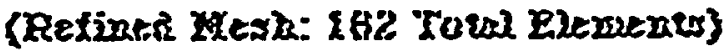

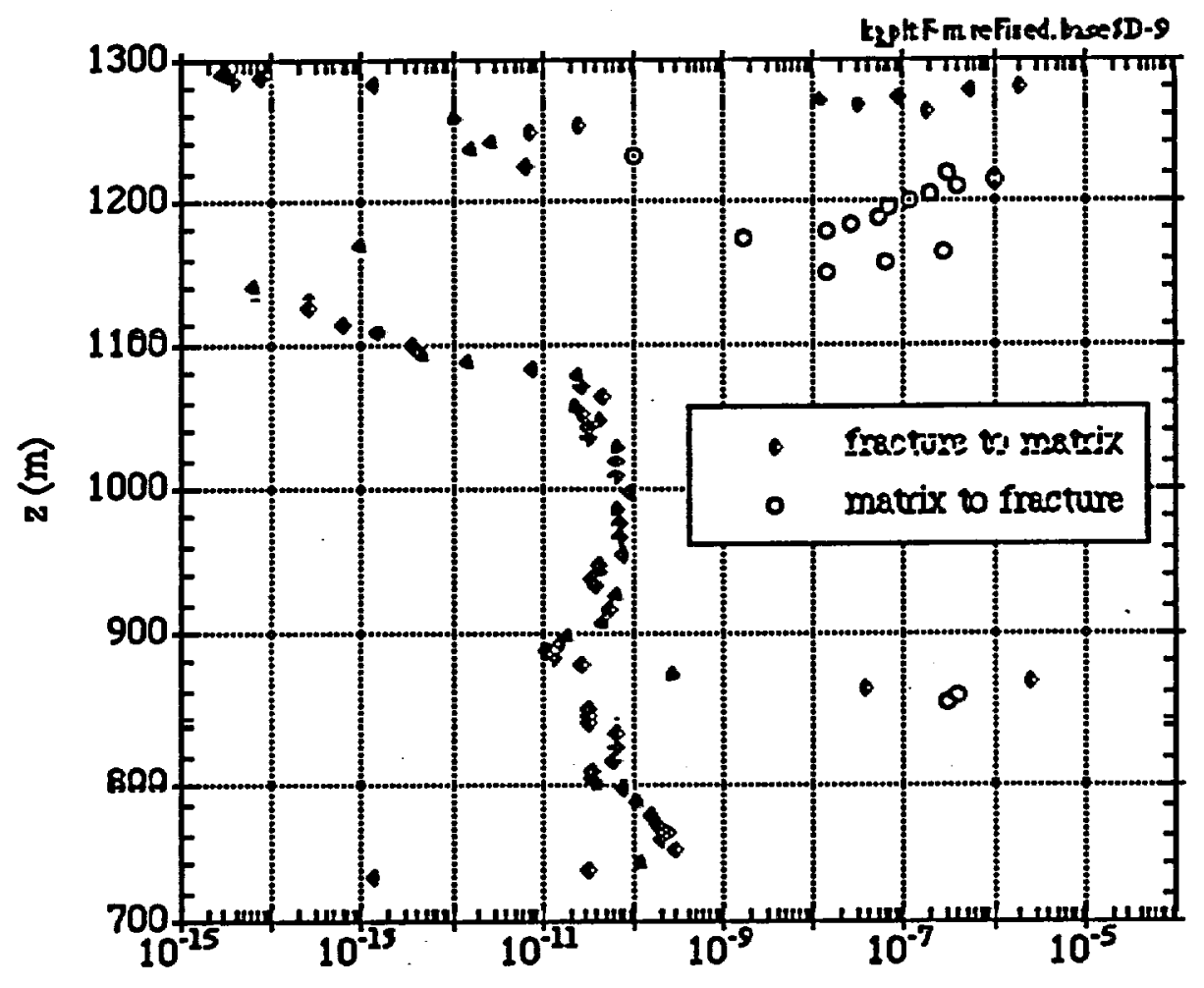

Mass Flow Betwreen Fractures and Matrix (kg/s) 


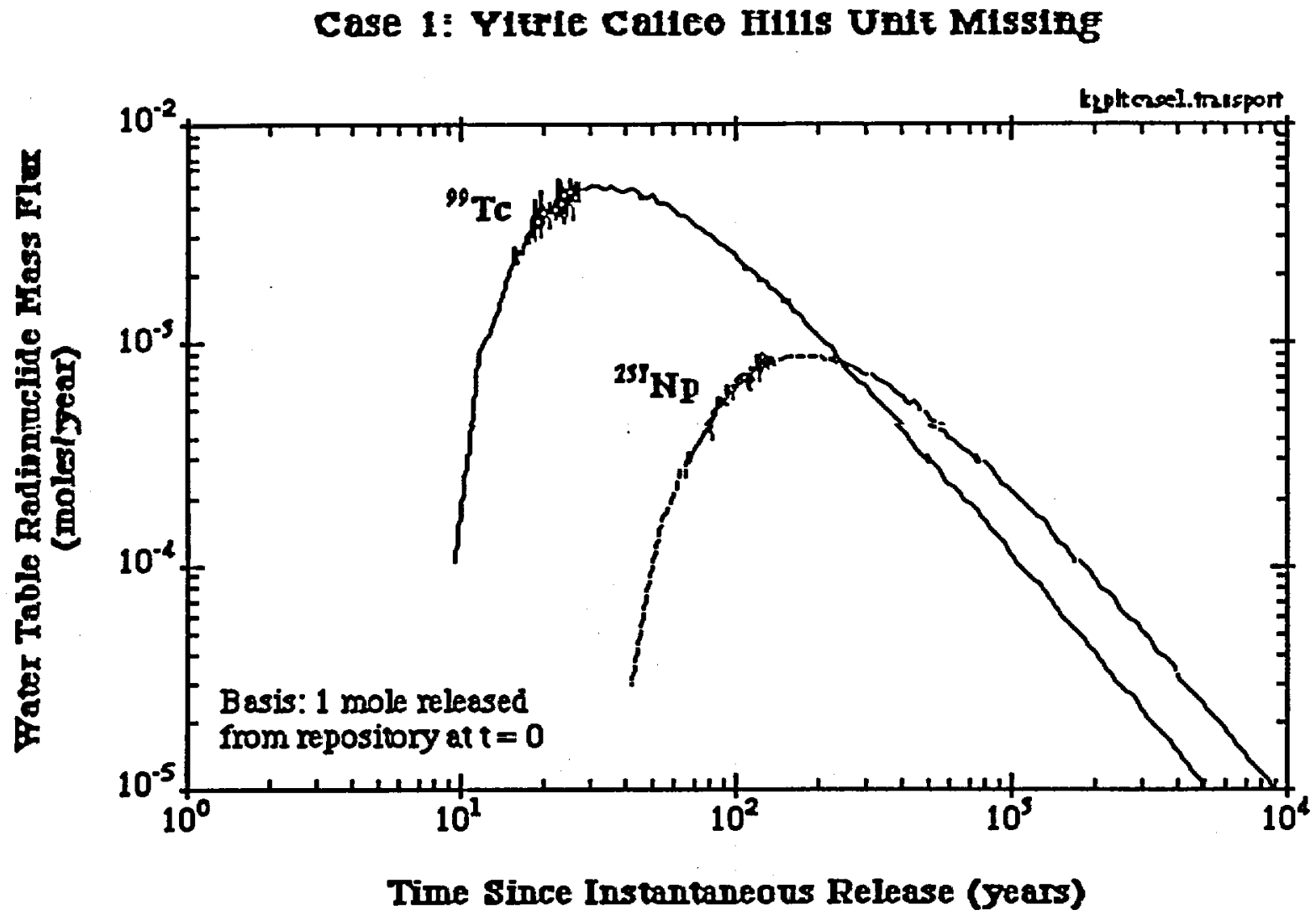

FIG 7 
Case 2: Yizfle Calleo Hils Ineluded

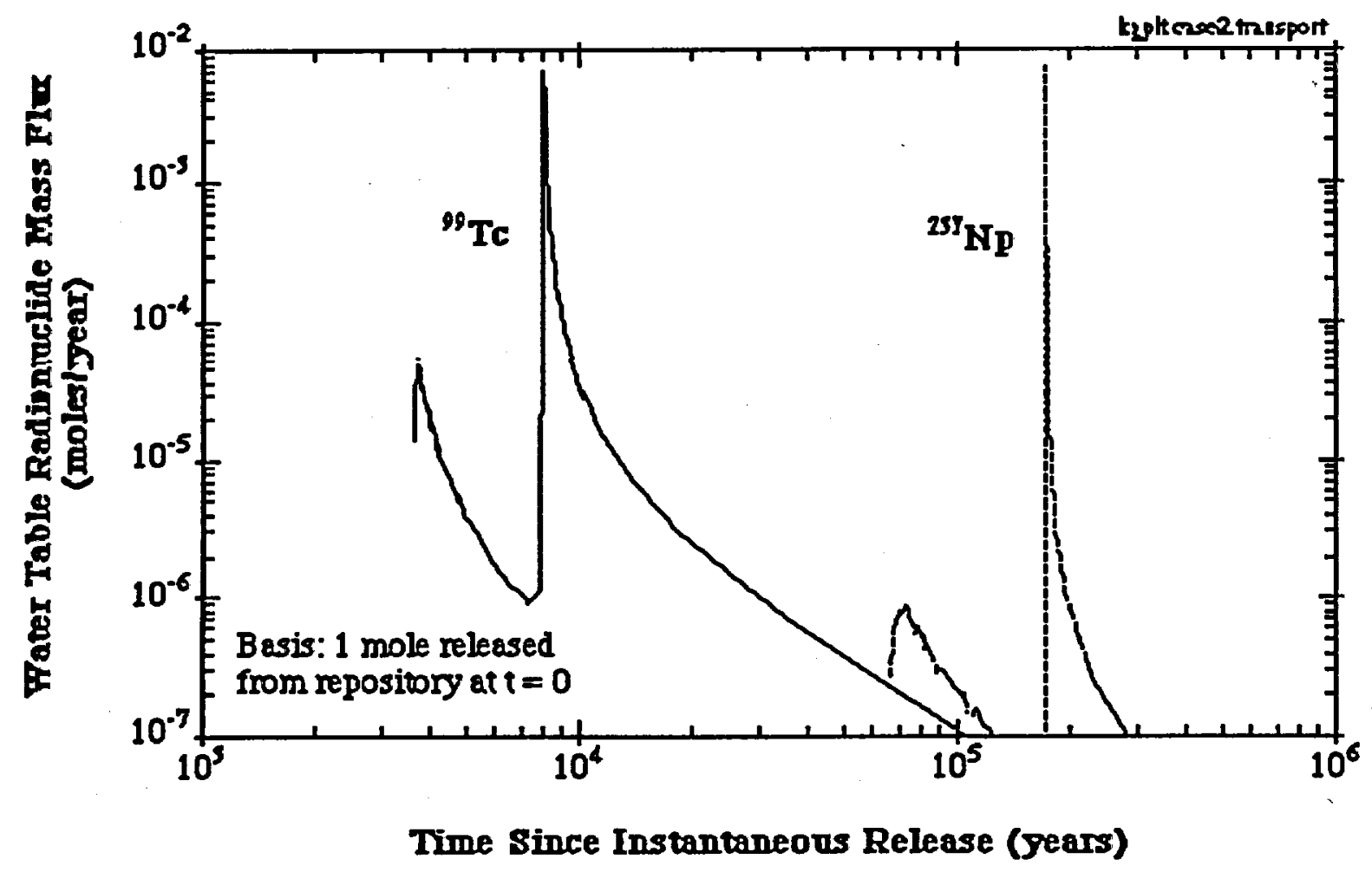

FIG 8 


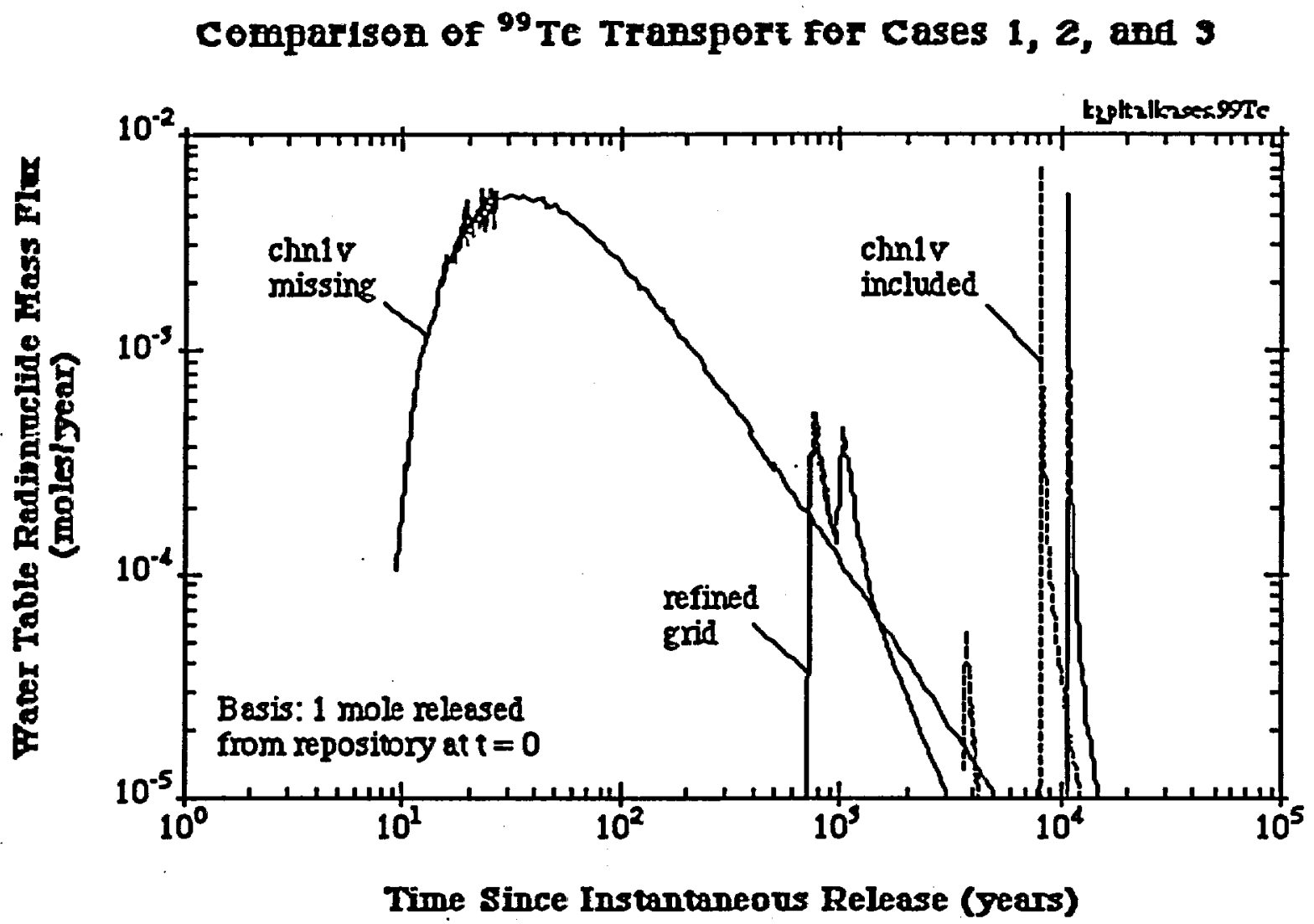

Fic $?$ 
Comparison of ${ }^{237} \mathrm{~Np}$ Transport for cases 1,2 , and 3

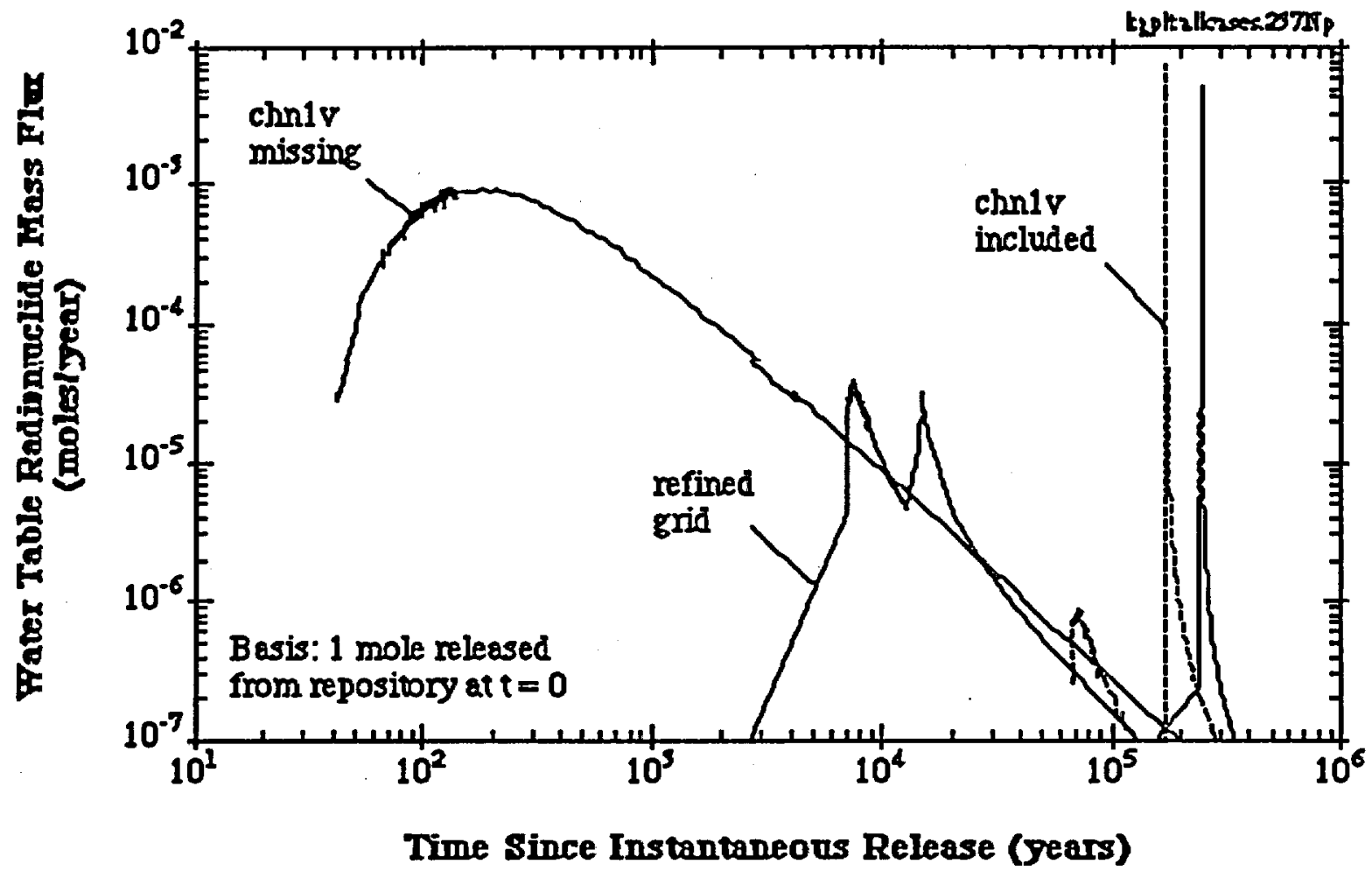

FiG 10 


\section{Comparison of Fracture and Matrix Saturations Using FEHM and TOUGH2}

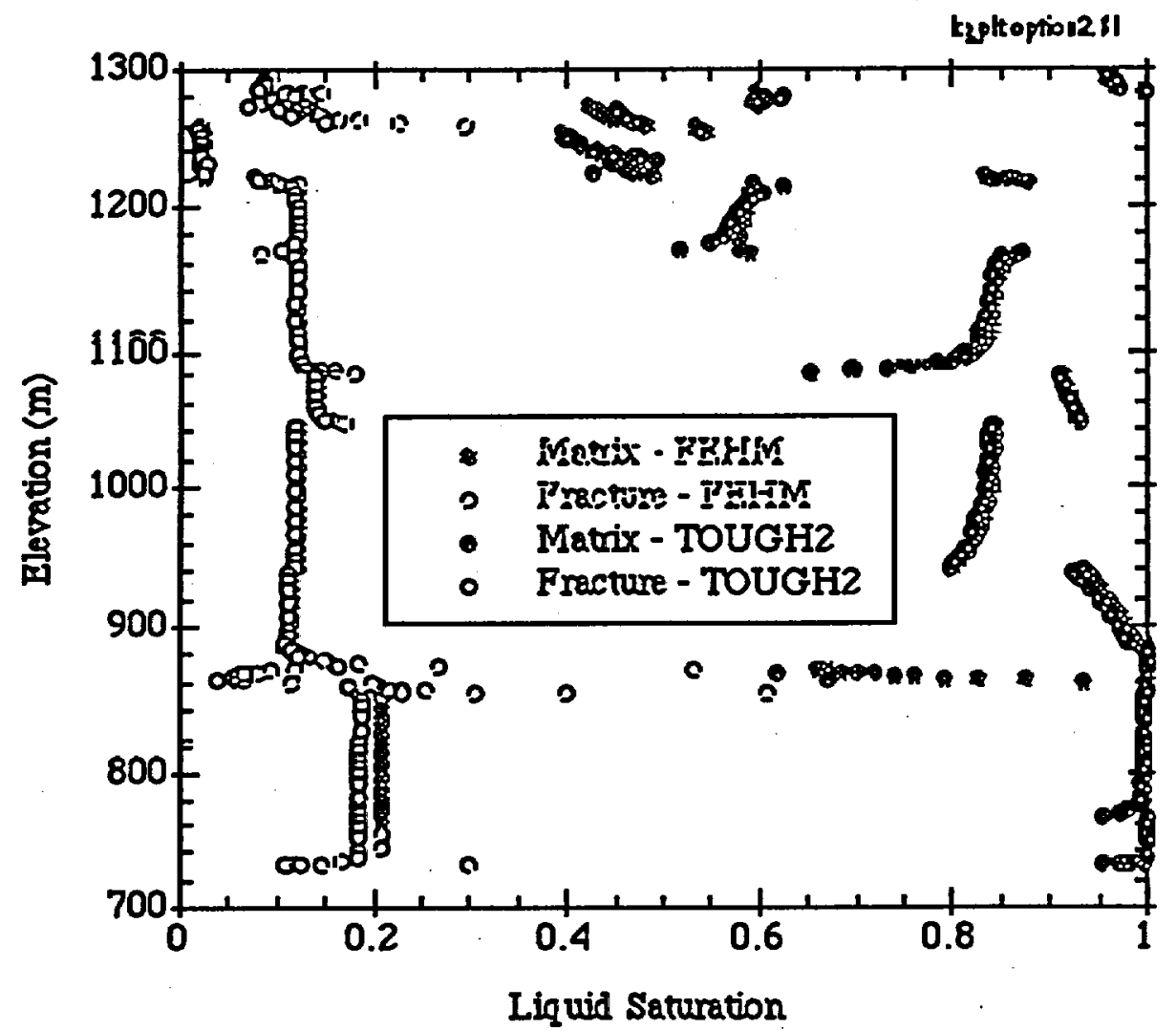


Comparison of Fracture and Matrix Normalized Flux Using FEHM and TOUGH2

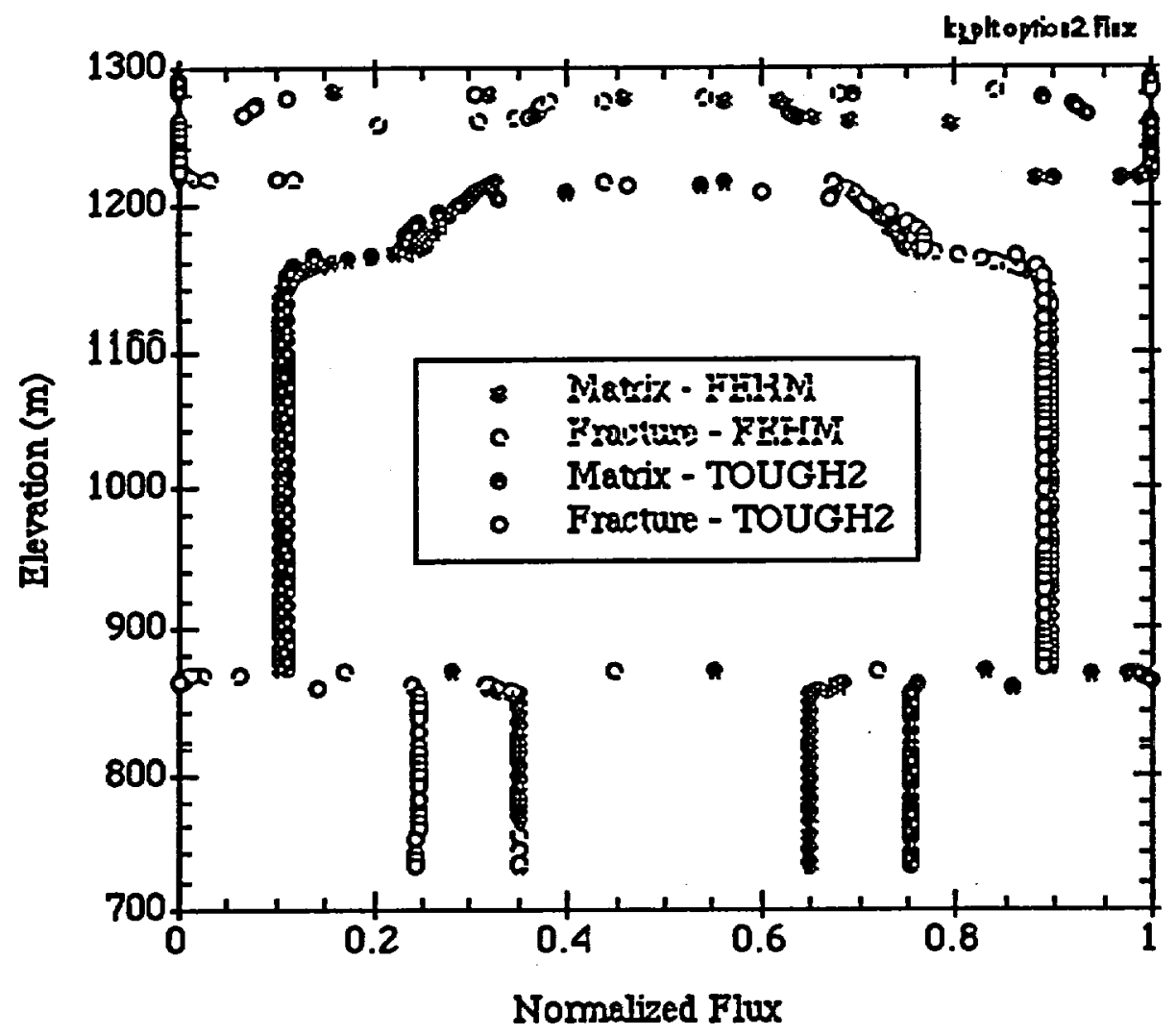

FIG 12 
Comparison of Fracture and Matrix Normalized Flux Using FEHM and TOUGH2 (Expanded Vier)
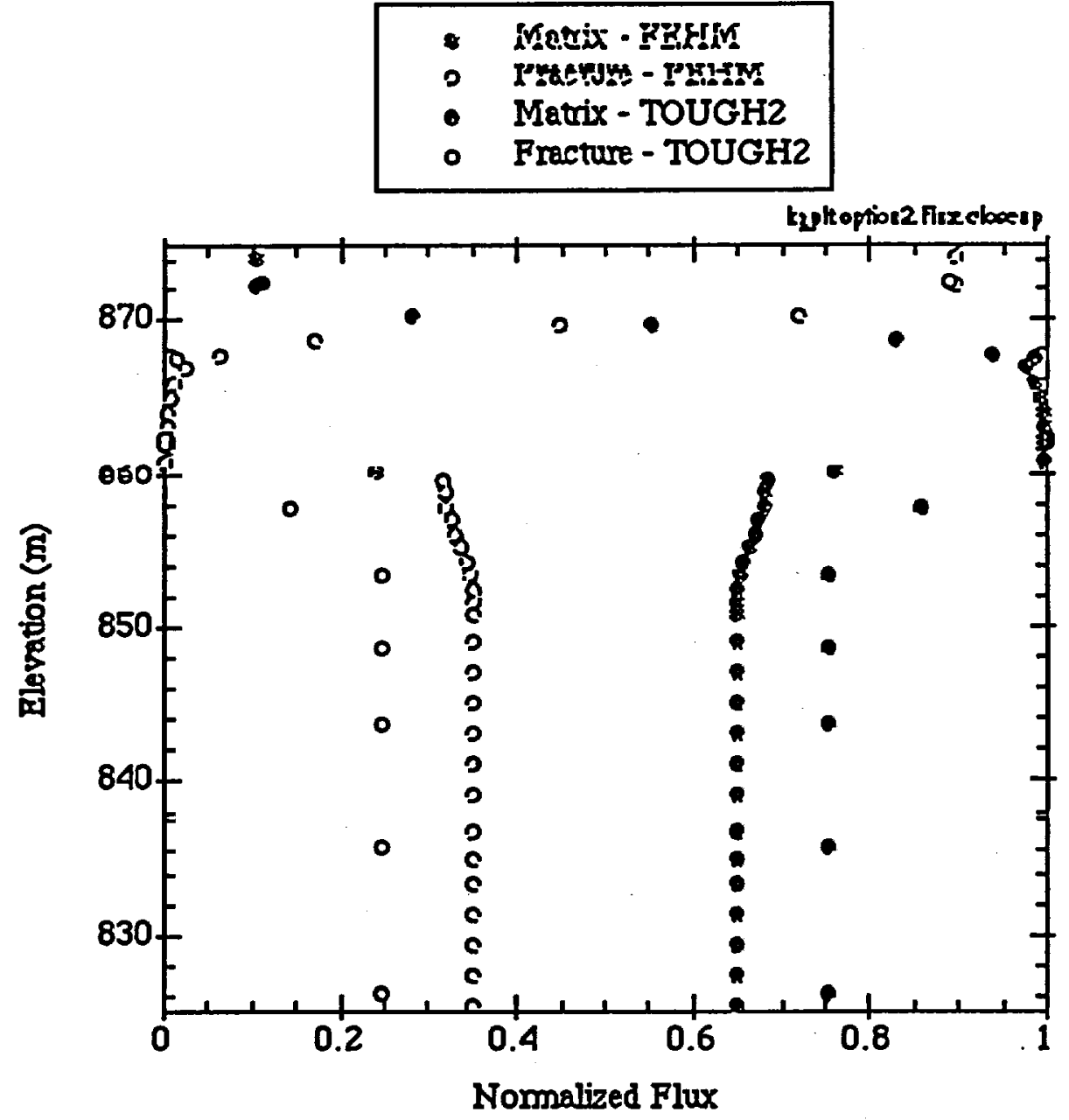

FIG 13 
Comparison of ${ }^{99}$ Tc Mass Flux at the Water Table Using FEHM and TOUGH2

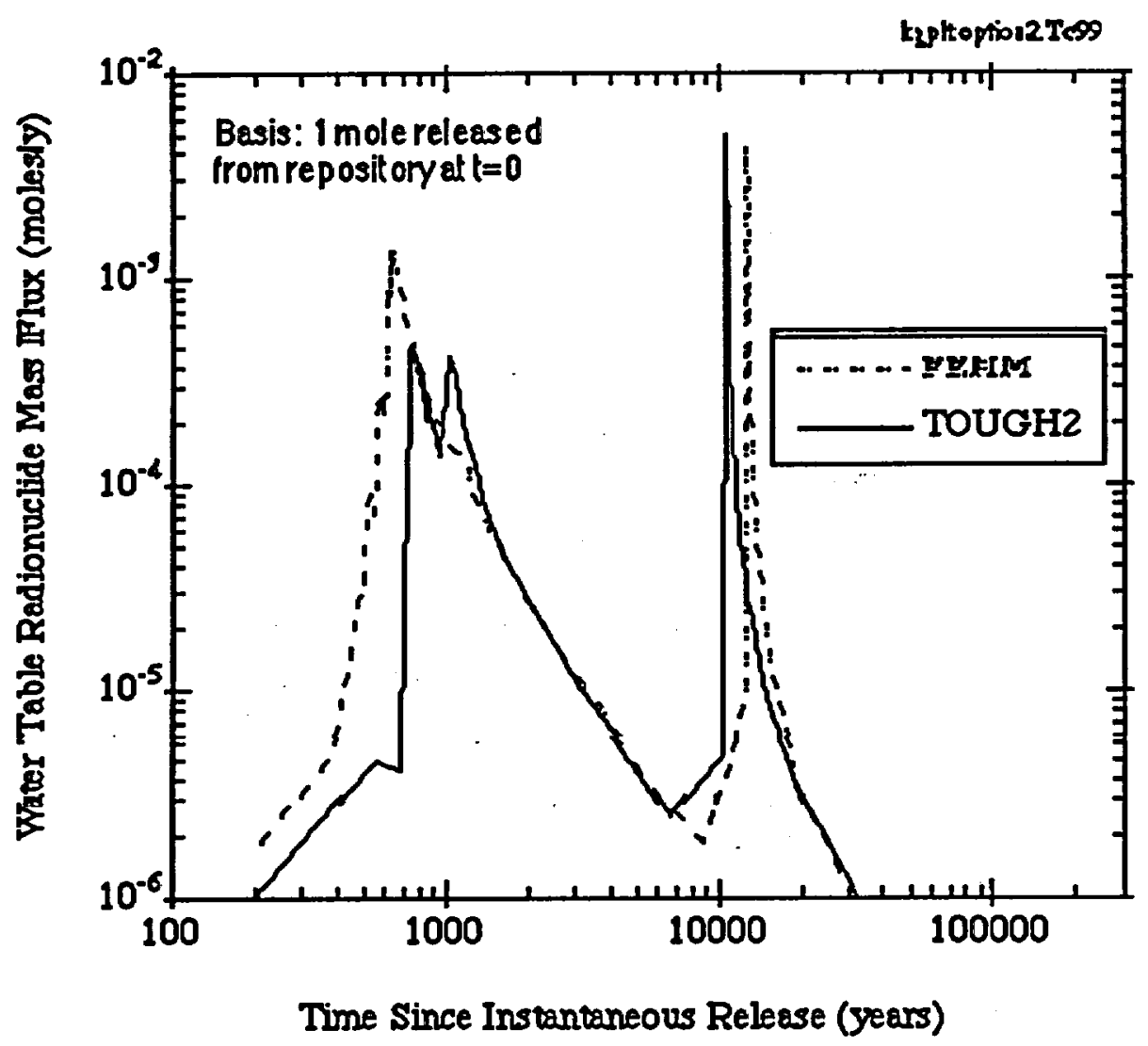

FIG 14 
Comparison of ${ }^{237} \mathrm{~Np}$ Mass Flux at the Water Table Using FEHM and TOU OH2

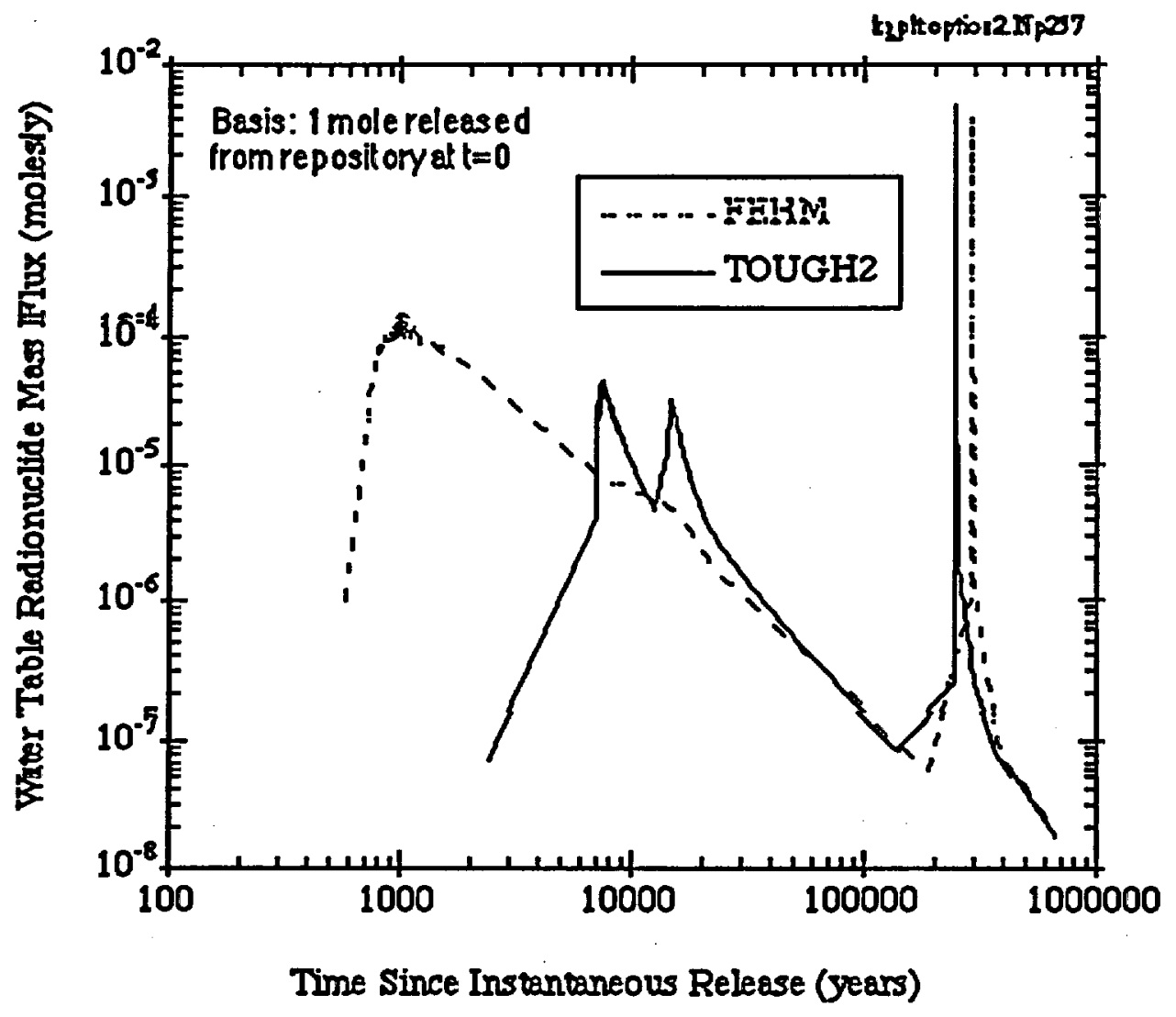

FIG 15 
TOUGH2 and FEHM Liquid Saturations

Using Harmonic $\mathbf{z}$ and Upstream $k r$

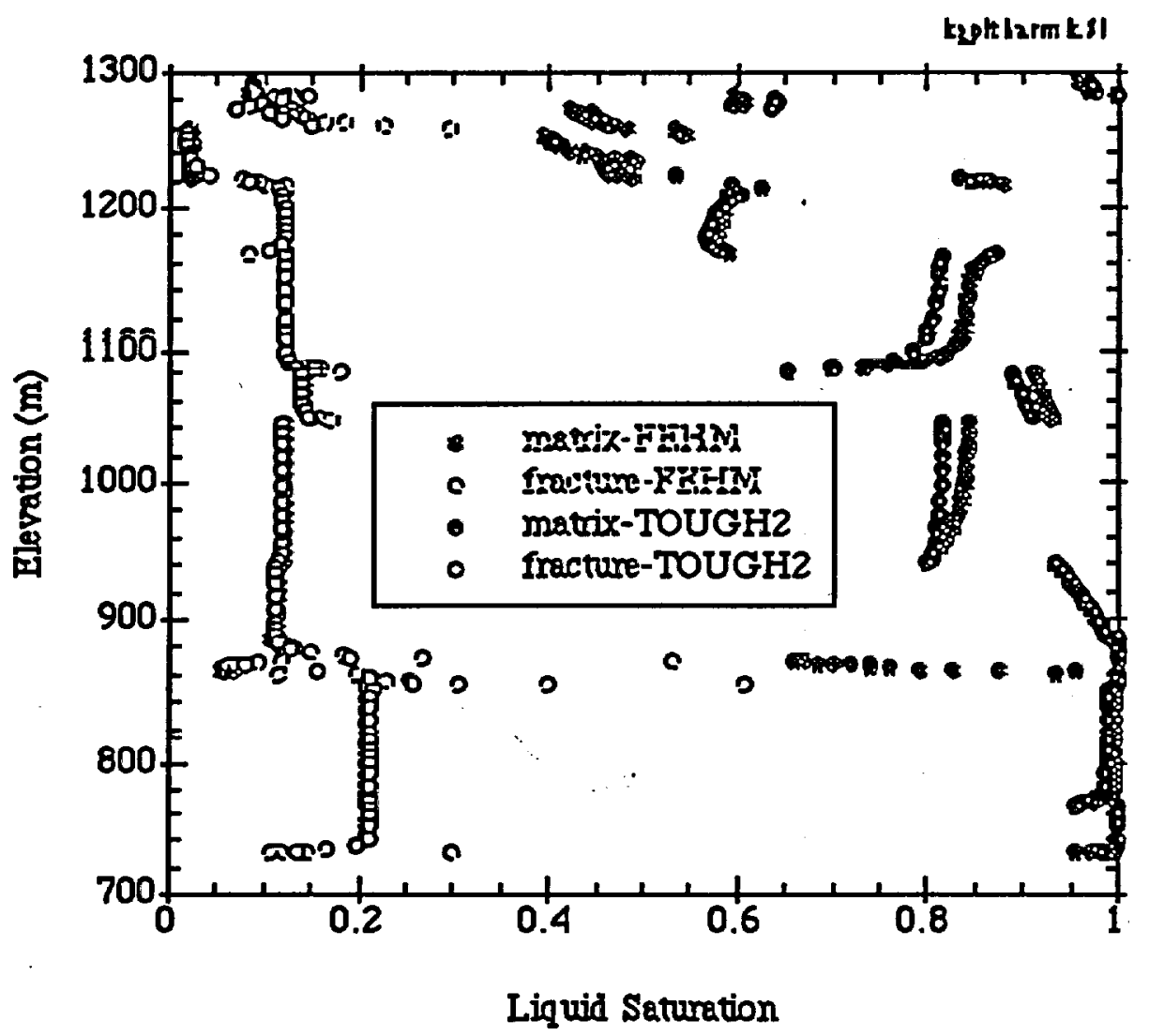

FIC 16 


\section{TOUGH2 and FEHM Normalized Mass Flov \\ Using Harmonic $\mathrm{k}$ and Upstream kr}

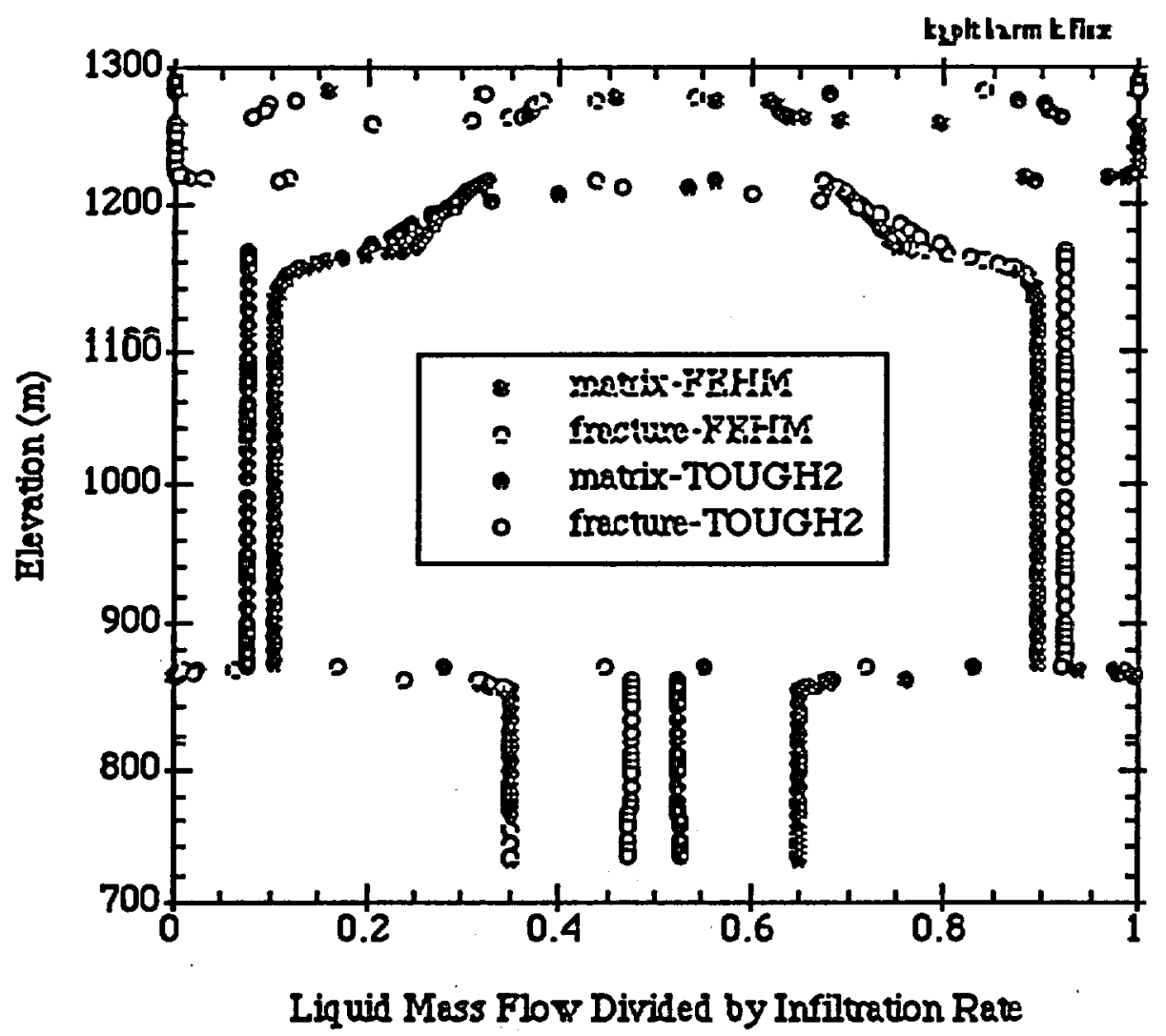

FIG 17 


\section{i}

(DTN: LB971100001254.002; TDIF: 306482)

\begin{tabular}{|c|c|c|c|c|c|c|c|c|}
\hline $\begin{array}{c}\text { horizontal } \\
\text { fracture } \\
\text { ermeability } \\
\text { (log) }\end{array}$ & \begin{tabular}{|l} 
Practure \\
porosity
\end{tabular} & $\begin{array}{c}\text { fracture } \\
\text { van } \\
\text { Genuchten } \\
\text { alpha (log) }\end{array}$ & \begin{tabular}{|c|} 
fracture \\
van \\
Genuchten \\
m (l)
\end{tabular} & $\begin{array}{l}\text { Tracture } \\
\text { ressidual } \\
\text { saturation }\end{array}$ & \begin{tabular}{|c} 
fracture \\
sattated \\
saturation
\end{tabular} & $\begin{array}{l}\text { fracture } \\
\text { frequency }\end{array}$ & $\begin{array}{l}\text { fracture-matrix } \\
\text { connection } \\
\text { area modfitier }\end{array}$ & $\begin{array}{l}\text { Model } \\
\text { Layer }\end{array}$ \\
\hline $\operatorname{og}(\mathrm{k})(\mathrm{m} 2)$ & $\boldsymbol{\pi}(-)$ & $\log (\mathbf{a f})(1 / \mathbf{P a})$ & $m f(-)$ & Slrm (-) & Sism (-) & $f(1 / m)$ & $\log (L)(-)$ & \\
\hline-11.22 & $2.33 \mathrm{E}-04$ & -3.53 & $\overline{0.492}$ & 0.01 & 1.0 & 1.020 & .3 .31 & tew11 \\
\hline-111.22 & $2.99 \mathrm{E}-04$ & -3.53 & $\overline{0.492}$ & $\overline{0.01}$ & $\overline{1.0}$ & 1.830 & -3.31 & tcw12 \\
\hline-12.62 & 7.05E-05 & -4.04 & $\overline{0.492}$ & $\overline{0.01}$ & $\overline{1.0}$ & 1.270 & $\overline{-3.31}$ & tew13 \\
\hline-12.28 & $4.84 \mathrm{E}-05$ & -2.96 & $\overline{0.492}$ & $\overline{0.01}$ & 1.0 & $\overline{0.870}$ & -0.96 & $p^{t n 21}$ \\
\hline-12.71 & $4.83 \mathrm{E}-05$ & -2.74 & $\overline{0.492}$ & $\overline{0.01}$ & $\overline{\overline{1.0}}$ & $\overline{\overline{0.290}}$ & $\overline{-0.15}$ & $\overline{p \tan 22}$ \\
\hline-12.59 & $1.30 \mathrm{E}-04$ & -2.47 & $\overline{0.492}$ & $\overline{0.01}$ & $\overline{1.0}$ & 0.290 & -0.16 & pton \\
\hline-13.21 & $6.94 \mathrm{E}-05$ & -3.03 & $\overline{0.492}$ & $\overline{0.01}$ & $\overline{\overline{1.0}}$ & 0.630 & $\overline{-0.32}$ & $p \tan 24$ \\
\hline$\overline{-13.11}$ & $3.86 \mathrm{E}-05$ & -3.71 & $\overline{0.279}$ & 0.10 & 1.0 & 0.650 & -0.32 & pen25 \\
\hline-12.00 & $8.92 \mathrm{E}-05$ & -4.40 & $\overline{\overline{0.481}}$ & $\overline{0.01}$ & $\overline{\overline{1.0}}$ & 1.100 & -0.30 & 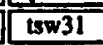 \\
\hline-12.15 & $1.29 \mathrm{E}-04$ & 4.03 & 0.488 & $\overline{0.01}$ & $\overline{1.0}$ & 1.010 & -4.54 & $15 \times 32$ \\
\hline-12.05 & \begin{tabular}{|l}
$1.05 E-04$ \\
\end{tabular} & $-\overline{-3.75}$ & $\overline{0.492}$ & $\overline{0.01}$ & 1.0 & $\overline{0.690}$ & -4.10 & tsw33 \\
\hline .12 .37 & $1.24 E-04$ & -4.01 & $\overline{0.492}$ & 0.01 & $\overline{1.0}$ & 1.880 & -3.81 & t5w34 \\
\hline-12.04 & $3.29 \mathrm{E}-04$ & $\overline{-3.96}$ & $\overline{0.492}$ & $\overline{0.01}$ & 1.0 & 1.810 & -1.11 & tosw35 \\
\hline-11.92 & $\overline{3.99 \mathrm{E}-04}$ & -3.88 & 0.492 & 0.01 & 1.0 & 2.100 & $\overline{-4.32}$ & $\longdiv { t s w 3 6 }$ \\
\hline-11.92 & $4.92 \mathrm{E}-04$ & -3.93 & $\overline{0.492}$ & $\overline{0.01}$ & $\overline{1.0}$ & 2.880 & -3.31 & tsw37 \\
\hline-13.62 & $1.10 \mathrm{E}-05$ & -2.95 & $\overline{\overline{0.492}}$ & 0.01 & $\overline{1.0}$ & 0.067 & $\overline{-0.74}$ & chlux \\
\hline -13.93 & $1.10 \mathrm{E}-05$ & -2.91 & $\overline{0.492}$ & $\overline{0.01}$ & $\overline{1.0}$ & 0.067 & $\overline{0.00}$ & ch22x \\
\hline-13.93 & $1.10 \mathrm{E}-05$ & -2.91 & $\overline{0.492}$ & 0.01 & $\overline{1.0}$ & 0.067 & 0.00 & ch33x \\
\hline$\overline{.13 .81}$ & $1.10 \mathrm{E}-05$ & $\overline{-2.94}$ & $\overline{0.492}$ & $\overline{0.01}$ & 1.0 & 0.067 & -0.30 & cch4xx \\
\hline-12.76 & $7.14 \mathrm{E}-05$ & -2.93 & 0.492 & $\overline{0.01}$ & $\overline{1.0}$ & 0.420 & -0.31 & chlve \\
\hline-12.54 & $7.14 \mathrm{E}-05$ & -2.93 & $\overline{\overline{0.492}}$ & $\overline{0.01}$ & $\overline{1.0}$ & 0.420 & $\overline{-0.31}$ & ch2ve \\
\hline-12.54 & $7.14 \mathrm{E}-05$ & -2.93 & $\overline{0.492}$ & $\overline{0.01}$ & $\overline{1.0}$ & 0.420 & -0.31 & ch3ve \\
\hline$=12.54$ & $\overline{7.14 E-05}$ & $\overline{-2.93}$ & $\overline{\overline{0.492}}$ & $\overline{0.01}$ & 1.0 & $\overline{0.420}$ & -0.31 & chave \\
\hline .12 .16 & 7.14E-05 & -2.85 & $\overline{0.492}$ & $\overline{0.01}$ & $\overline{\overline{1.0}}$ & 0.420 & $\begin{array}{c}-3.29 \\
\end{array}$ & (pp3yp \\
\hline-12.16 & $7.14 \mathrm{E}-05$ & -2.85 & $\overline{0.492}$ & 0.01 & $\overline{1.0}$ & $\overline{0.420}$ & -3.29 & $b \overline{s v b}$ \\
\hline-12.16 & $7.14 \mathrm{E}-05$ & -2.85 & $\overline{0.492}$ & $\overline{0.01}$ & $\overline{1.0}$ & 0.420 & $\overline{-3.29}$ & tm3vt \\
\hline -13.19 & $1.10 \mathrm{E}-05$ & $-\overline{-3.43}$ & $\overline{0.492}$ & 0.01 & $\overline{1.0}$ & 0.067 & -0.31 & $p p 2 z p$ \\
\hline 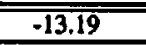 & $1,10 \mathrm{E}-05$ & $\overline{-3.43}$ & 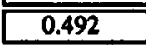 & $\overline{0.01}$ & $\overline{1.0}$ & 0.067 & $\overline{-0.31}$ & $6 \sqrt{226}$ \\
\hline
\end{tabular}

TABLE 2 

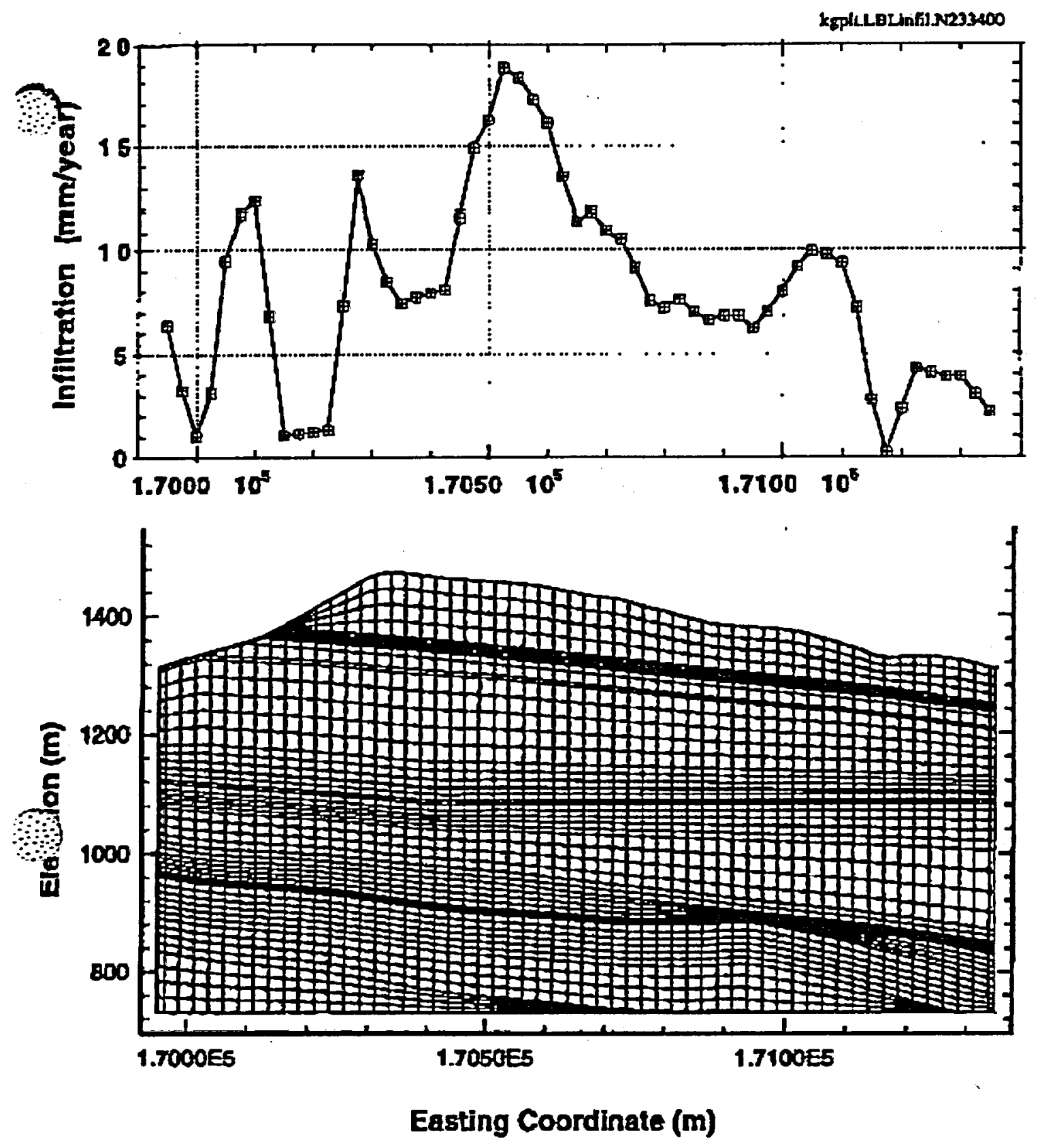

FIG 18 

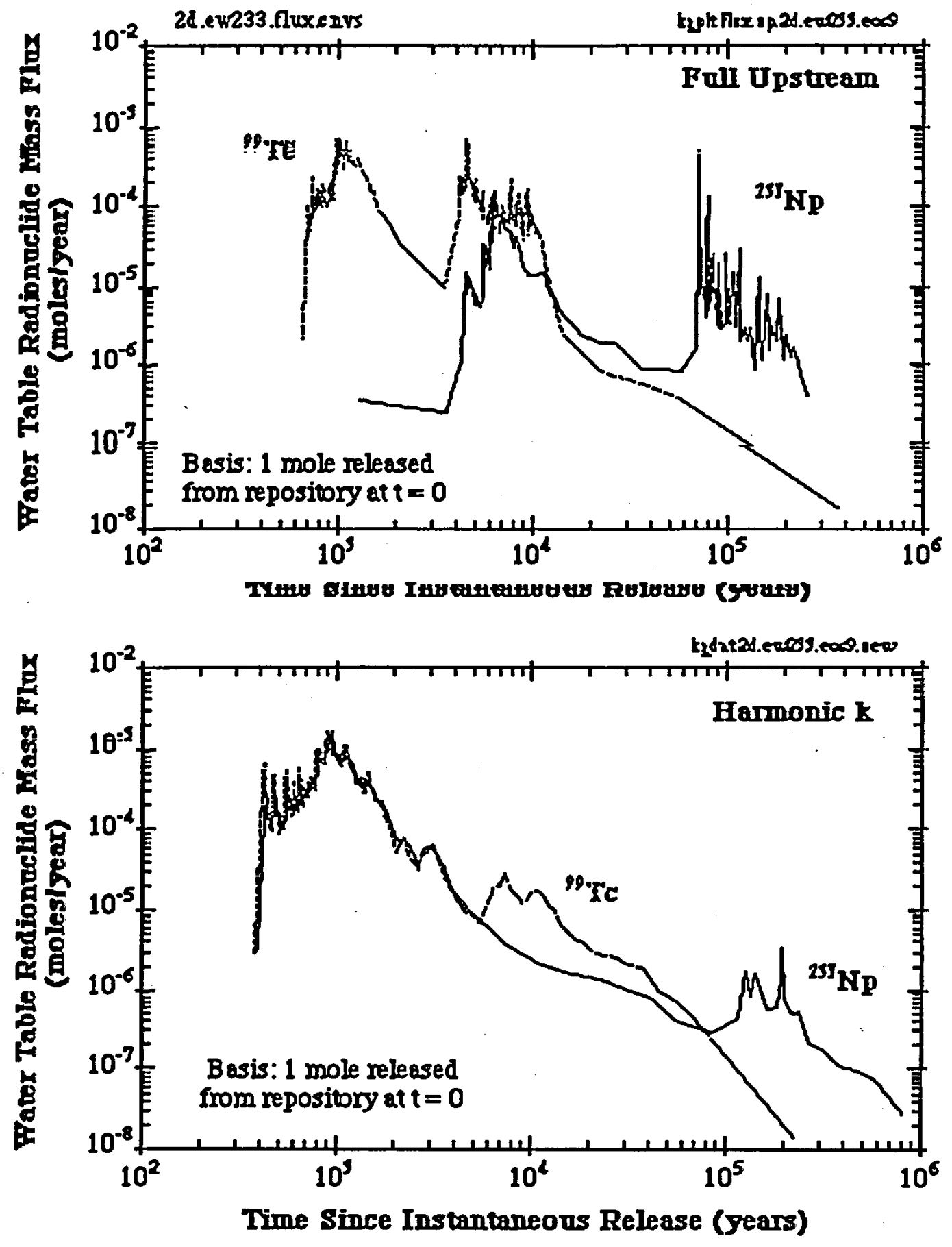

FIG 19 

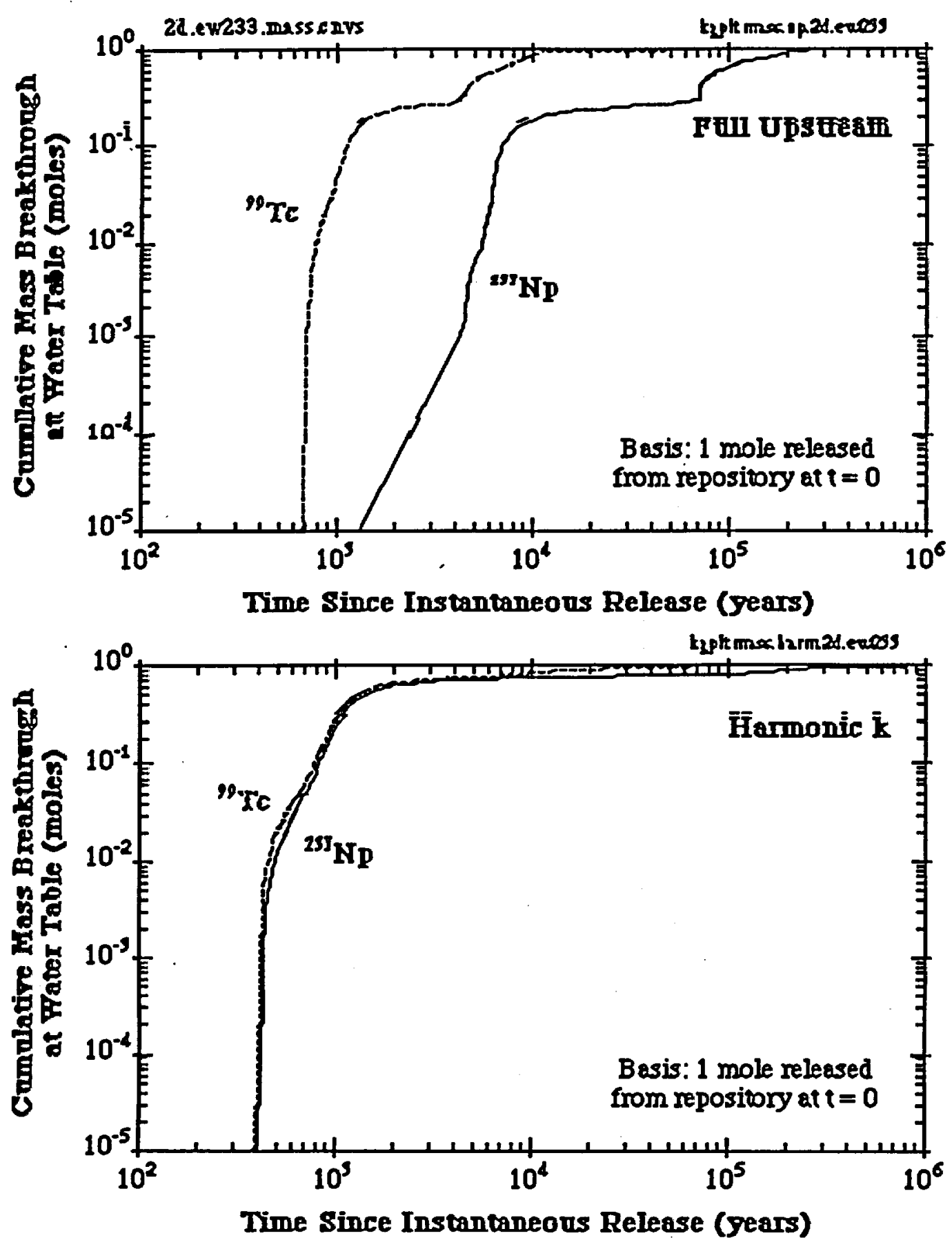

FIG 20 

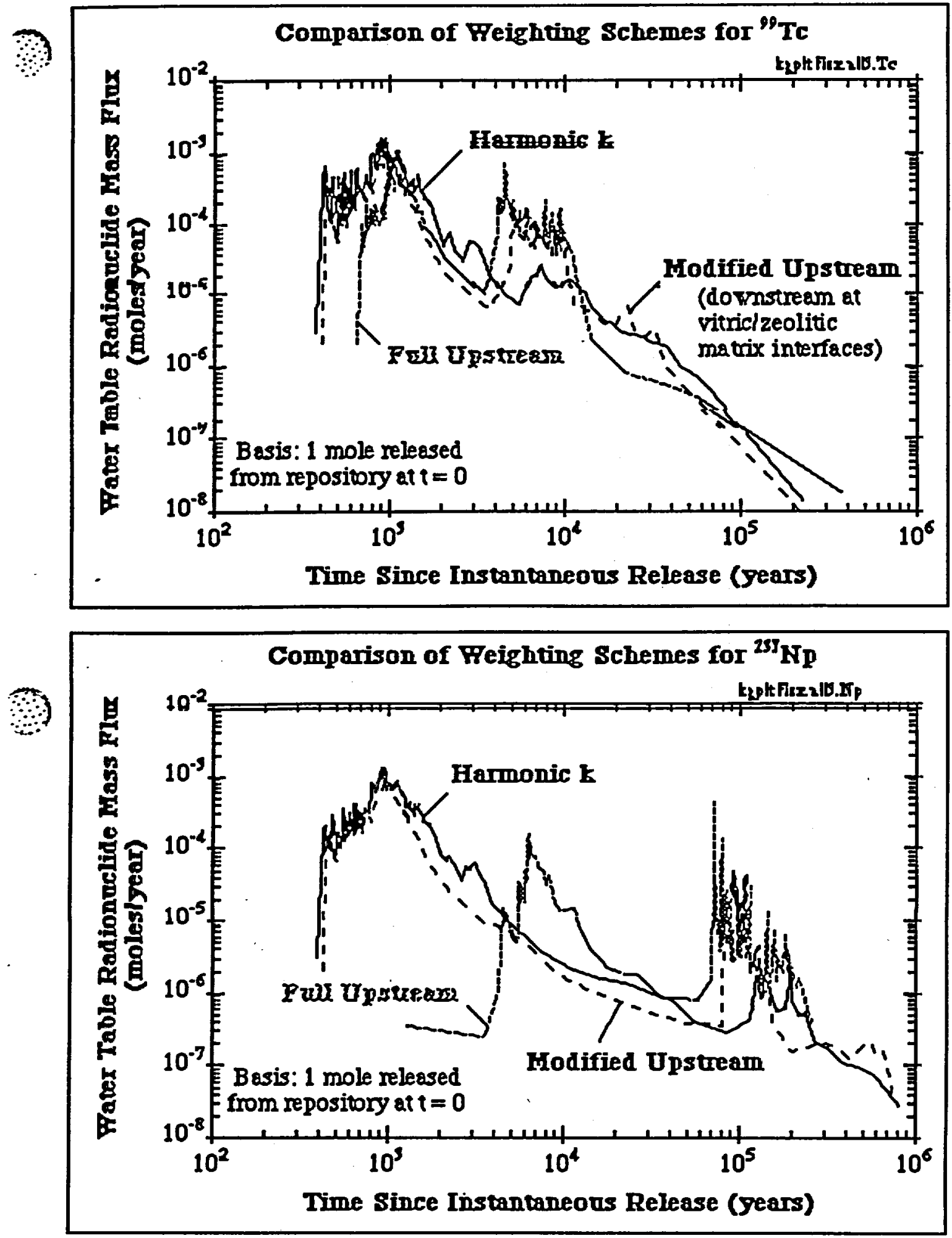

FIG \& 


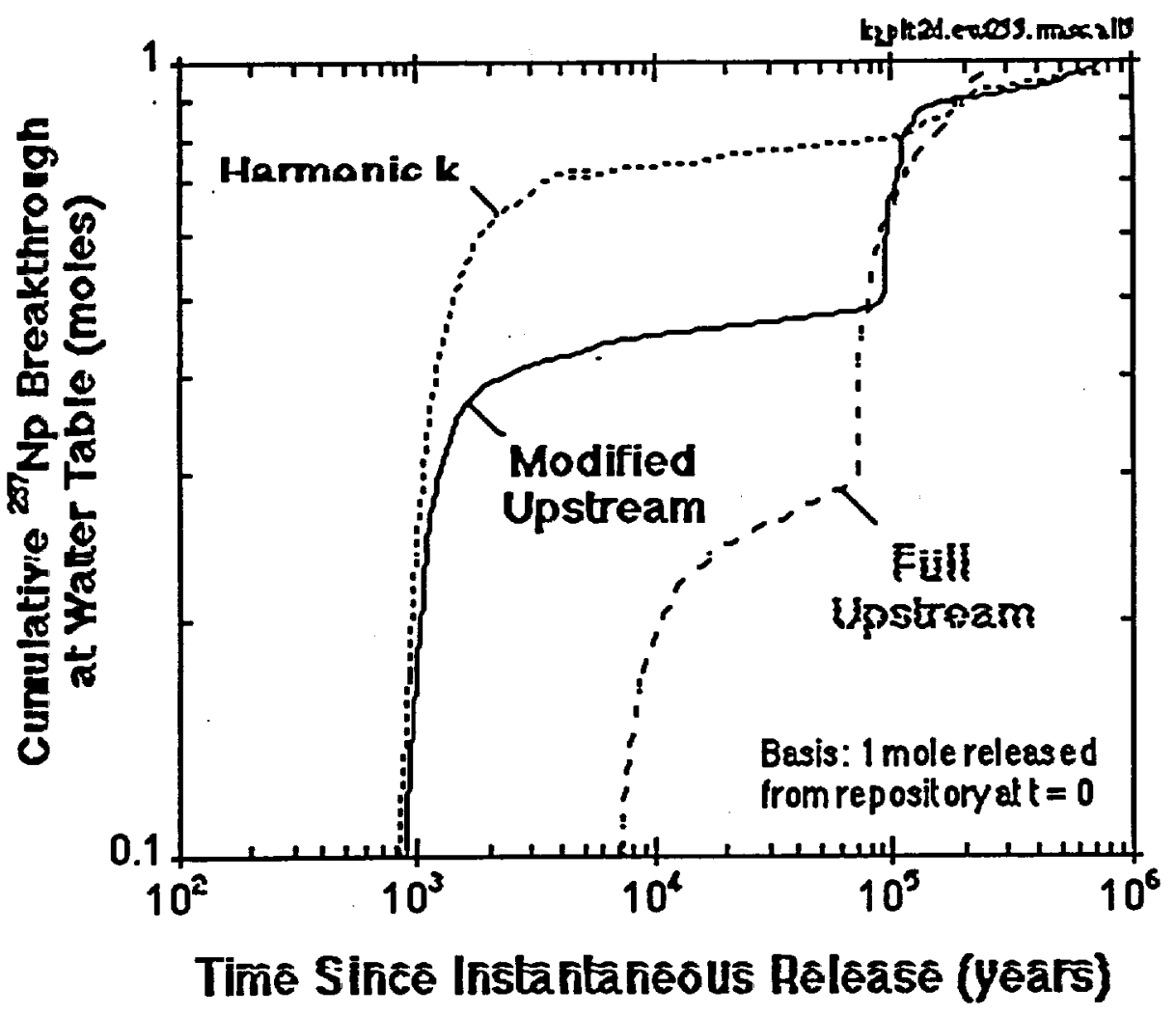

FIG 22 

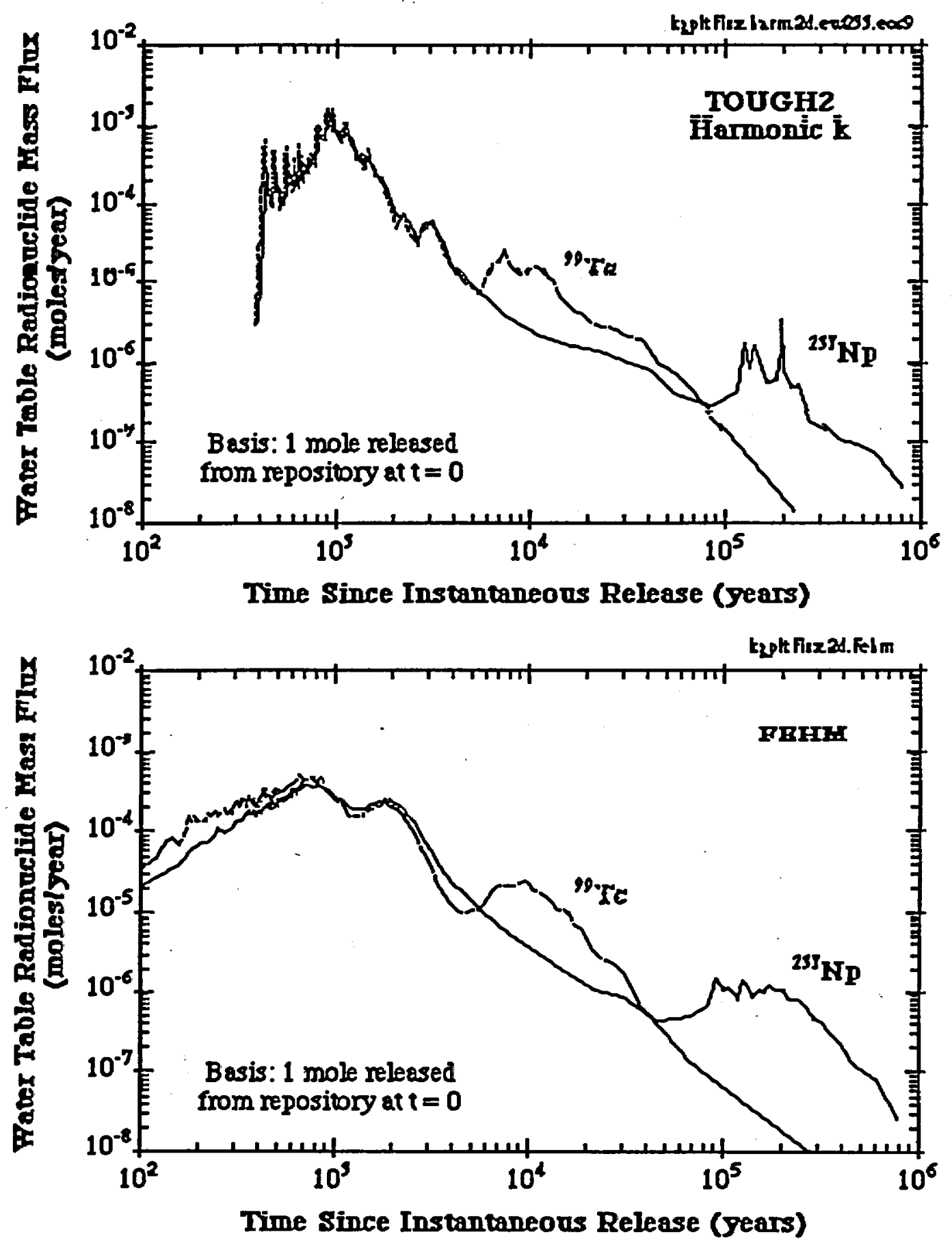

FiG 23 